
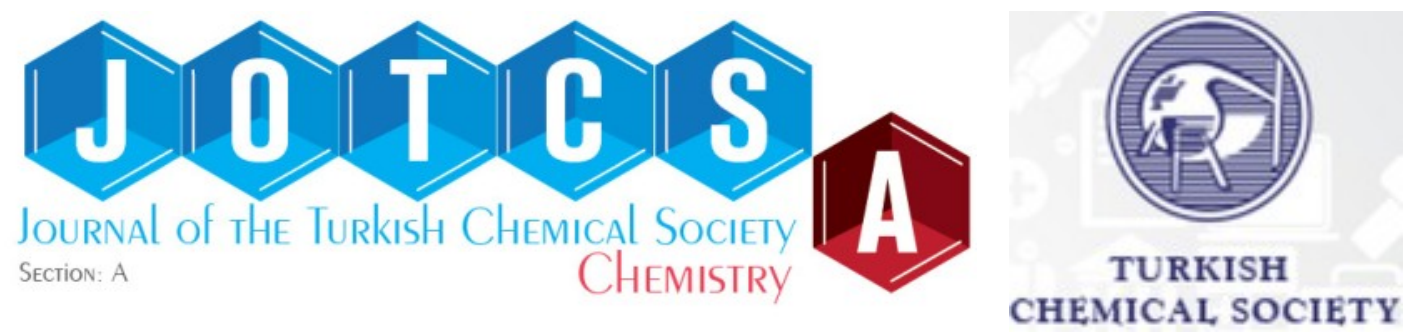

\title{
Optimization and Characterization of Cellulose Nanocrystal Production from Aseptic Tetra Pak Food Packaging Waste
}

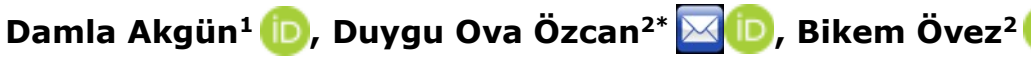 \\ ${ }^{1}$ Selkasan Kagit ve Paketleme Malzemeleri İmalat San ve Tic. A. Ş., Manisa, Turkey \\ ${ }^{2}$ Ege University, Faculty of Engineering, Department of Chemical Engineering, Izmir, Turkey
}

\begin{abstract}
Cellulose fibers were extracted from the recycled Tetra Pak aseptic food package wastes, and high value-added cellulose nanocrystals (CNC) were produced by the acidic hydrolysis. At the optimum $\mathrm{H}_{2} \mathrm{SO}_{4}$ concentration of $25 \% \mathrm{w}$, the whiteness index of CNC obtained at $30{ }^{\circ} \mathrm{C}$ for 30 min CNC was $84.42 \%$, while it was $56.00 \%$ for $50{ }^{\circ} \mathrm{C}$ for $60 \mathrm{~min}$ CNC. The effects of temperature and time on the hydrolysis yield were optimized by the Central Composite Design and the maximum yield was determined at the condition where the temperature was high and the time was the lowest. The physical and structural properties of different CNCs were investigated using several characterization techniques. The FTIR and TGA analyses of the CNCs obtained at different temperatures and times showed similar spectra and degradation temperatures with each other, respectively. The crystallinity index of alkaline-treated cellulose calculated from the XRD patterns was much lower than those of all of the CNCs. According to AFM measurements and SEM micrographs, it was confirmed that as the temperature and time increased, the diameters of the CNCS were reduced. The lowest diameter value was measured as $175 \mathrm{~nm}$ at $50{ }^{\circ} \mathrm{C}$ for 60 min CNC, whereas, on the other hand, the highest diameter value was measured as $403 \mathrm{~nm}$ at $30^{\circ} \mathrm{C}$ for $30 \mathrm{~min} \mathrm{CNC}$.
\end{abstract}

Keywords: Cellulose nanocrystals, extraction, waste recovery, Tetra Pak, Central Composite Design.

Submitted: September 16, 2021. Accepted: December 17, 2021.

Cite this: Akgün D, Ova Özcan D, Övez B. Optimization and Characterization of Cellulose Nanocrystal Production from Aseptic Tetra Pak Food Packaging Waste. JOTCSA. 2022;9(1):131-48.

DOI: https://doi.org/10.18596/jotcsa.996450.

*Corresponding author. E-mail: duygu.ova@ege.edu.tr.

\section{INTRODUCTION}

Today, in the European Union, nearly 100 million liters of liquids and beverages such as milk and fruit juice are packaged in cartons which means 977,000 tons of packaging material and waste (1). More than 179 million Tetra Pak packages were being sold worldwide in $2014(2,3)$. After the consumption of food or the liquid product, most of packages end up as household and/ or municipal solid waste. At this stage, treatment of the waste arises as an important problem for sustainable processes. The recycling of Tetra Pak packaging has the benefit of minimizing the need for virgin material, decreases the air pollution, also contributes to energy savings and provides a reduction in $\mathrm{CO}_{2}$ emissions (2). Some parts of these packages are systematically recuperated, sorted, and then recycled. According to declared data by Tetra Pak (2021), number of recycled Tetra Pak packages increased from 32 billion in 2010 to 50 billion in 2020 which is approximately $27 \%$ of the total number of packages produced (4).

In the recycling of Tetra Pak packages, one of the most important parts is the recycling of the paperboard layer, which contains mostly cellulose, hemicellulose, and lignin, because of its natural biodegradable content (5). As a chemical raw material, cellulose has been mostly used in the form of fibers or derivatives for a wide range of products and materials such as plastics, composites textiles, a food structuring agent, photographic films, and rayon (6). It exists in the cell walls of various 
plants, for maintaining their structure and also in a wide variety of living species, such as bacteria, algae, fungi, and tunicates (7). Furthermore, cellulose is renewable, biodegradable and biocompatible, so it is considered as an alternative to nondegradable fossil fuel-based polymers (8). Different cellulose sources have different cellulose content such as banana peel, nut shell, and corn stover having $13.2,25-30$ and $38 \%$ cellulose content, respectively. The properties like crystallinity or thermal degradation might be varied depending on the cellulose content of the starting material and treatment method/condition (9).

Increased demand for high-performance materials with tailored mechanical and physical properties has resulted in searching for different materials like nanocellulose which is recently the most attractive renewable material for advanced applications. Nanocellulose can be divided to three types which are cellulose nanocrystal, cellulose nano fiber, and bacterial cellulose (10). Cellulose nanocrystals are mainly produced from cellulose fibers involving selective hydrolysis of amorphous cellulose parts, resulting in high crystallinity of particles. Rod-like shaped cellulose nanocrystals are renewable, biodegradable, biocompatible, and nontoxic ecofriendly materials.

The cellulose in the Tetra Pak waste sources always contains substantial lignin and hemicellulose fractions. These materials should be removed to obtain pure cellulosic fibers prior to the production of cellulose nanocrystals (11). The alkali treatment is good for removing the impurities such as lignin, hemicellulose, pectin, and waxes in the fibers. Besides, it can expose the larger area of cellulose (12). The following bleaching procedure contributes to the removal the residual phenolic molecules like lignin that was refractive to alkali treatments and part of the hemicellulose yielding a white cellulose material suitable for a more effective production of cellulose nanocrystals (3). The purpose of this bleaching treatment is to break down phenolic compounds or molecules with chromophoric groups present in lignin, and to remove the by-products, and thus whitening the material. Bleaching might be performed by chlorine based agents such as $\mathrm{NaOCl}$ or $\mathrm{NaClO}_{2}$ and oxygen-based agents such as $\mathrm{H}_{2} \mathrm{O}_{2}$ or ozone. $\mathrm{NaOCl}$ or $\mathrm{NaClO}_{2}$ are cheap oxidizing agents which make it possible to render the removal of lignin efficiently. $\mathrm{H}_{2} \mathrm{O}_{2}$, used as a precursor in sodium chlorite treatments, can break alkalineresistant linkage which is formed between lignin and hemicellulose after alkaline treatment, and also act as an oxidizing agent to delignify lignocellulosic fiber. If oxygen-based agents are used, the bleaching process takes more time (13).

In this study, the necessity of purifying the recycled cellulose fibers from the Tetra Pak packages used as starting material and the variation of the processing conditions on the reaction efficiency were investigated. In order to investigate the success of the valorization of Tetra Pak packages, the physical and structural properties of the cellulose nanocrystals obtained from hydrolysis, at various processing conditions such as $\mathrm{H}_{2} \mathrm{SO}_{4}$ concentration, temperature, and time were examined using some characterization techniques and the yield was optimized.

\section{EXPERIMENTAL SECTION}

\section{Chemicals and Methods}

The recycled Tetra Pak which is used as a cellulose source was supplied from the waste management company Selkasan Kagit ve Paketleme Malzemeleri İmalat San ve Tic. A. Ş. (Manisa, Turkey). Sodium hydroxide $(\mathrm{NaOH})$ in the form of granules for alkali treatment, sodium hypochlorite $(\mathrm{NaOCl})$ used as a bleaching agent, and for hydrolysis, 97\% pure sulfuric acid $\left(\mathrm{H}_{2} \mathrm{SO}_{4}\right)$ were purchased from Merck (Darmstadt, Germany). All the chemicals were reagent grade and distilled water was utilized as the diluent solvent. Commercial microcrystalline cellulose powder was purchased from Sigma Aldrich (Ireland) with dimension of $20 \mu \mathrm{m}$ used as the reference standard.

The product material, nanocellulose was extracted from paperboard based recycled liquid food packages, which were selected milk and juice packages. The purification and isolation steps of the whole process involve cellulose extraction, alkali treatment, bleaching, and the production of cellulose nanocrystals (CNC) as shown in Figure 1. 


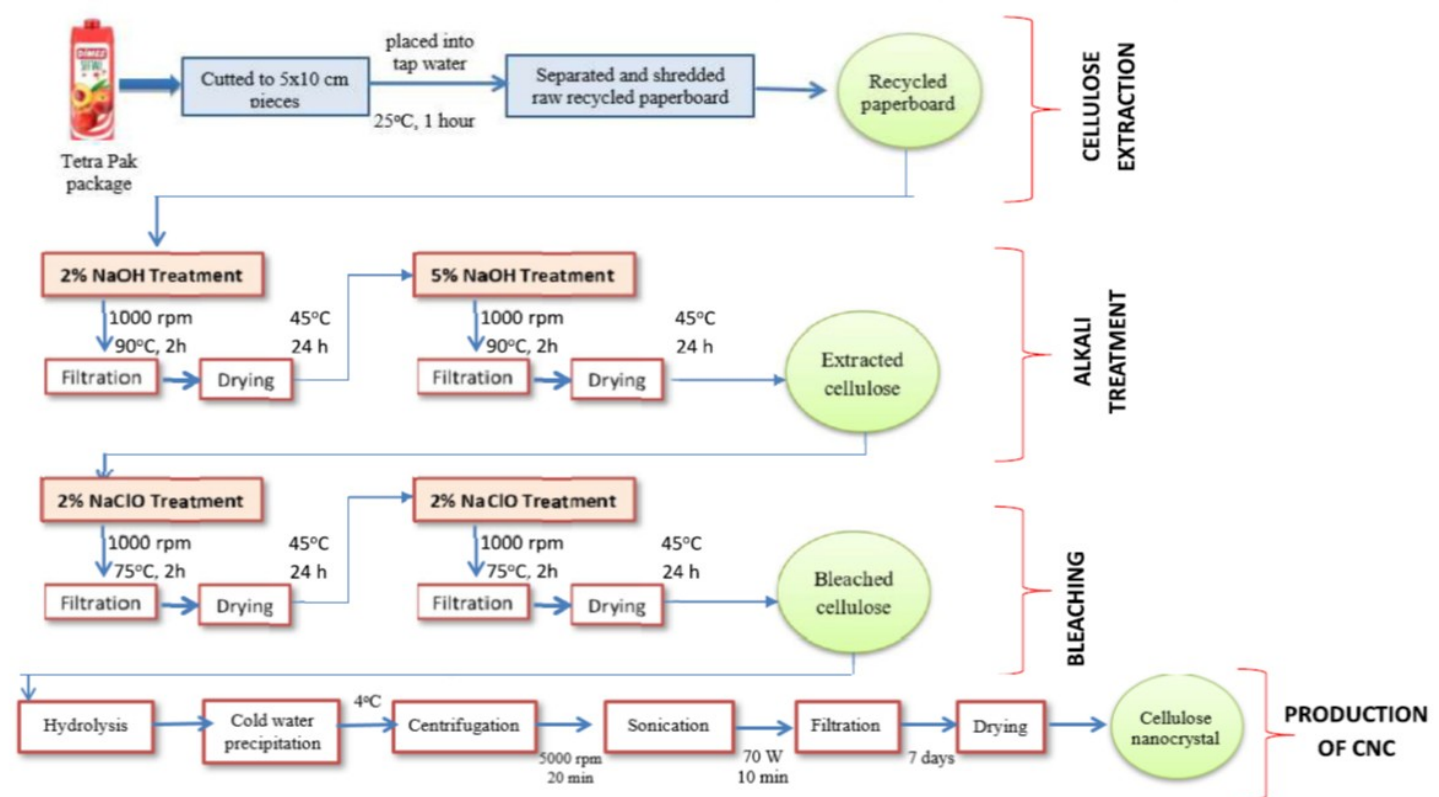

Figure 1: Flow diagram of production of nanocrystal cellulose from Tetra Pak waste packages.

\section{Cellulose Extraction from Tetra Pak Waste Packages}

For easier separation of the paper layer from the other two layers, Tetra Pak packages were cut into $5 \times 10 \mathrm{~cm}$ pieces which are shown as Figure $2(a)$. Then they were placed into a bowl which was full of water at room temperature for 1 hour. After 1 hour in water, the paperboard layer was peeled off as shown in the Figure 2 (b), not completely separated from polyethylene and labeled as raw recycled cellulose. To increase the surface area, the raw recycled cellulose was shredded into pieces about $1 \times 1 \mathrm{~cm}$ as shown in the Figure 2 (c). At the end of this step, the raw recycled paperboard was ready for the alkaline treatment.

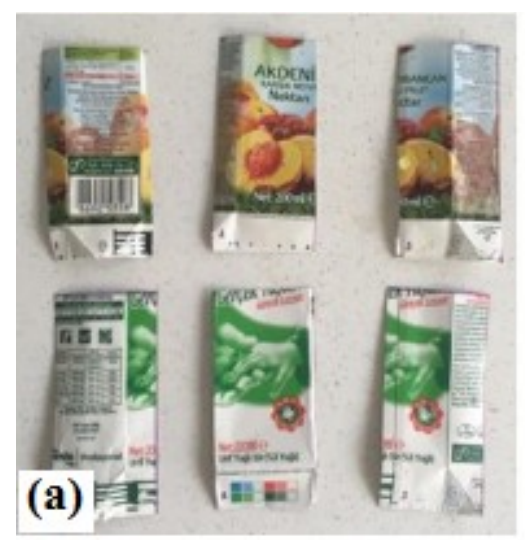

Figure 2: (a) Tetra Pak packages of $5 \times 1$ package, and

(b)

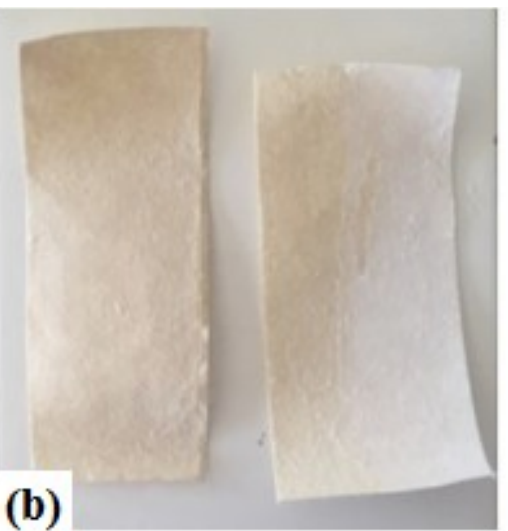

(c)

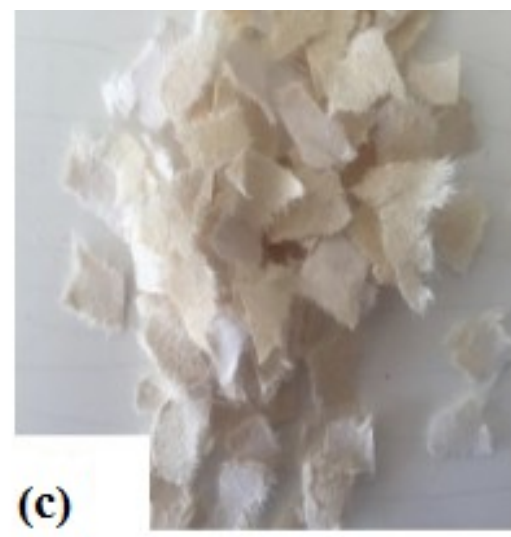

\section{Alkaline Treatment}

The extracted raw cellulose was treated with a $2 \%$ w aqueous $\mathrm{NaOH}$ solution with a $\mathrm{pH}$ of 12 at a solid to liquid ratio of $1: 100$. The purpose of a $2 \% \mathrm{w}$ aqueous $\mathrm{NaOH}$ treatment is to remove the different impurities such as waxes, pectin, proteins, soluble mineral salts, and silica ash etc., present in the raw material. Then the mixture was placed onto a multi hotplate WiseStir type SMHS-6 magnetic stirrer at $90^{\circ} \mathrm{C}$ at $1000 \mathrm{rpm}$ for 2 hours (3). The cellulose fibers obtained were filtered and washed with distilled water until a neutral $\mathrm{pH}$ was reached in order to avoid any reactions in the following steps. The filtered cellulose fibers were dried at $50{ }^{\circ} \mathrm{C}$ for 24 hours in a closed air-circulating oven with normal room air (14). Figure 3 (a) and (b) show filtered and dried alkaline-treated cellulose after alkaline treatment with a $2 \% \mathrm{w} \mathrm{NaOH}$. 


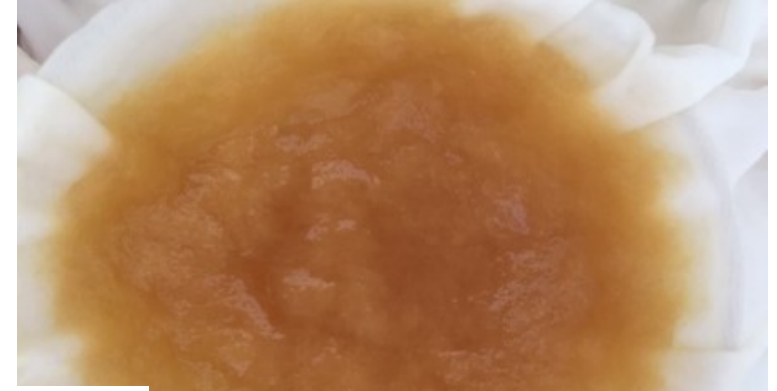

(a)

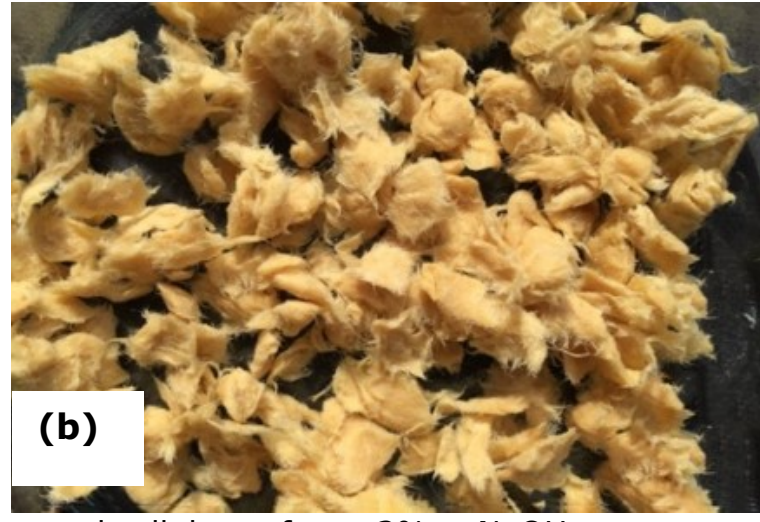

Figure 3: (a) Filtered and (b) dried alkaline-treated cellulose after a $2 \% \mathrm{w} \mathrm{NaOH}$ treatment.
The dried cellulose fibers were submitted to a second alkali treatment using a $5 \% \mathrm{w}$ aqueous $\mathrm{NaOH}$ solution with a $\mathrm{pH}$ of 13.5 at a solid to liquid ratio of $1: 100$. The purpose of the subsequent alkali treatment using a $5 \% \mathrm{w}$ aqueous $\mathrm{NaOH}$ solution specifically targeted a reduction of the lignin content in the recycled fibers without inducing swelling.
Then the mixture was again stirred at $90^{\circ} \mathrm{C}$ at 1000 rpm for 2 hours and then the filtered and washed cellulose fibers were dried at $40{ }^{\circ} \mathrm{C}$ for 24 hours as described above. At the end of the cellulose extraction process, the obtained cellulose fibers are named as alkaline-treated cellulose as shown in Figure 4 (a) and (b).
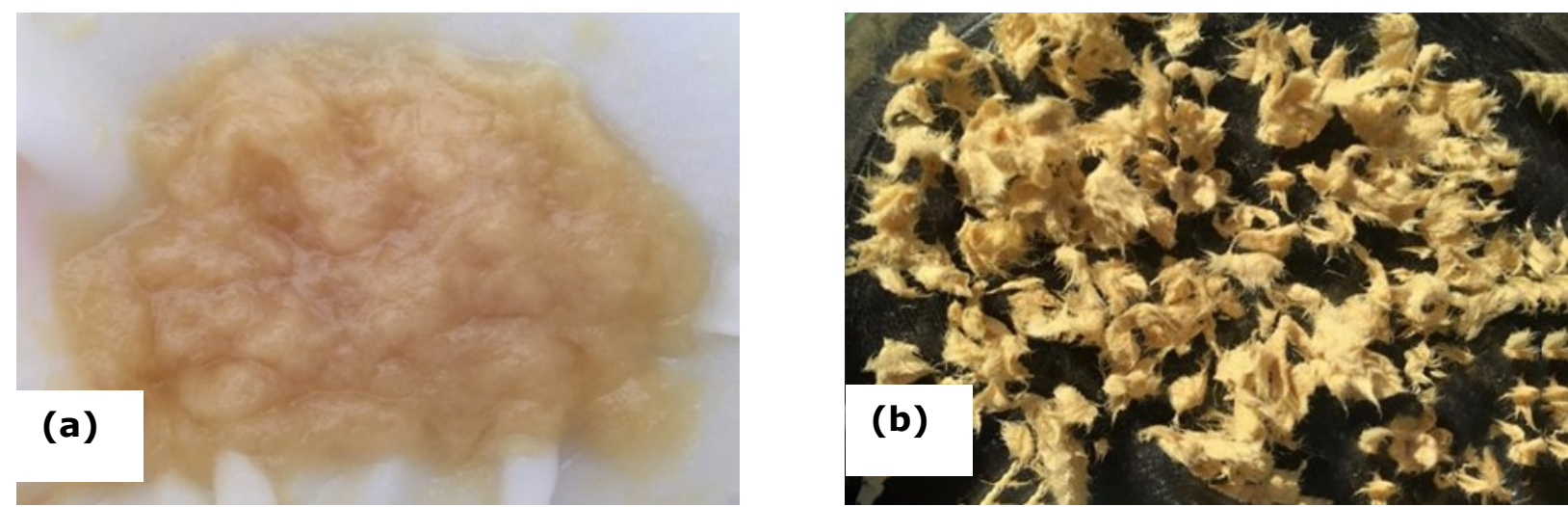

Figure 4: (a) Filtered and (b) dried alkaline-treated cellulose after a $5 \% \mathrm{w} \mathrm{NaOH}$ treatment.

\section{Bleaching}

Alkaline-treated cellulose bleached twice with a $5 \%$ $w$ aqueous $\mathrm{NaOCl}$ solution. The cellulose biomass was treated with a $5 \% \mathrm{w}$ aqueous $\mathrm{NaOCl}$ solution at a solid to liquid ratio of $1: 100$ (15). The mixture was placed onto a magnetic stirrer at $75^{\circ} \mathrm{C}$ at $1000 \mathrm{rpm}$ for 2 hours. For the second bleaching, the same procedure was repeated. Similar to the alkali treatment, the filtered and washed bleached cellulose was dried at $50{ }^{\circ} \mathrm{C}$ for 24 hours. The filtered and dried bleached cellulose after the first and second bleachings are illustrated in Figures 5 and 6 , respectively.
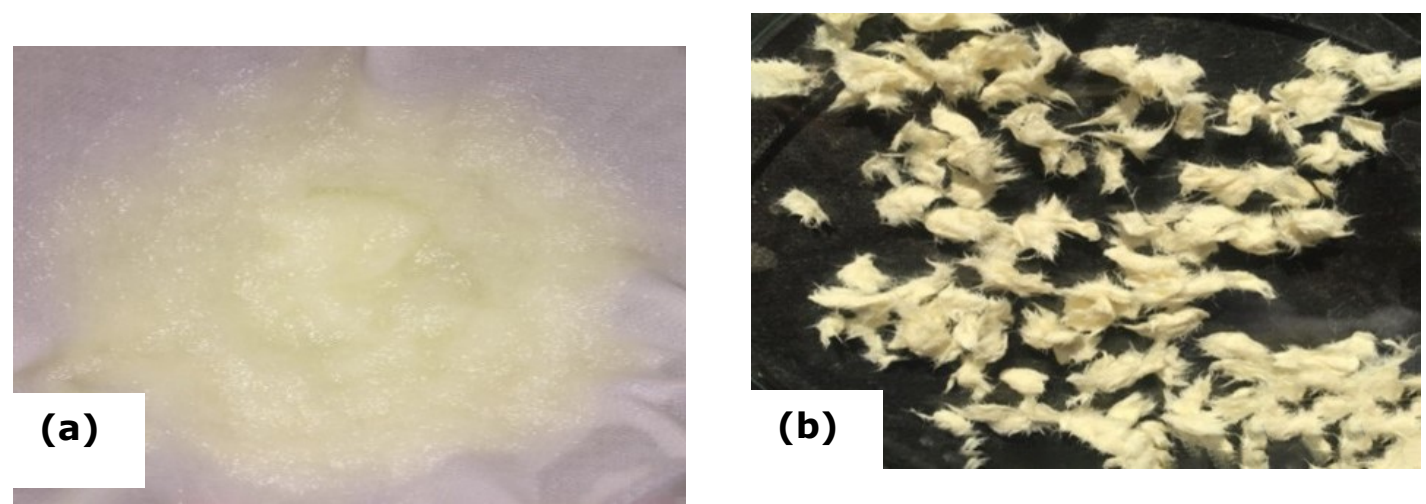

Figure 5: (a) Filtered and (b) dried alkaline-treated cellulose after the first 5\% w $\mathrm{NaOCl}$ treatment. 

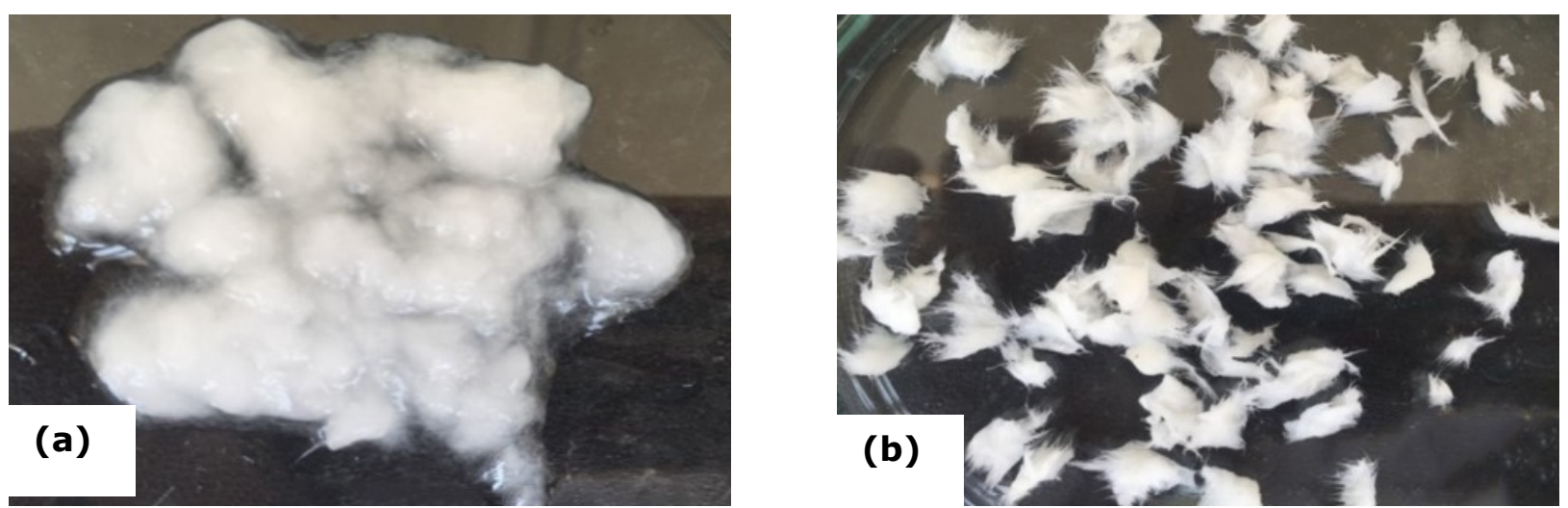

Figure 6: (a) Filtered and (b) dried alkaline-treated cellulose after the second $5 \% \mathrm{w} \mathrm{NaOCl}$ treatment.

The improved whiteness of the alkaline-treated, first and second bleached cellulose samples under

mechanical stirring are shown in Figure 7 (a), (b), and (c), respectively.

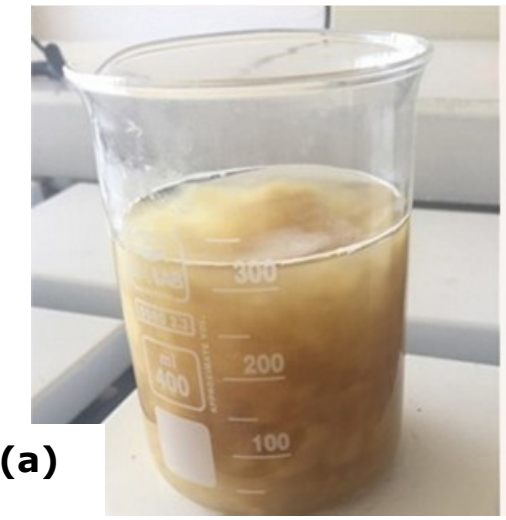

Figure 7: (a) Alkaline-treated

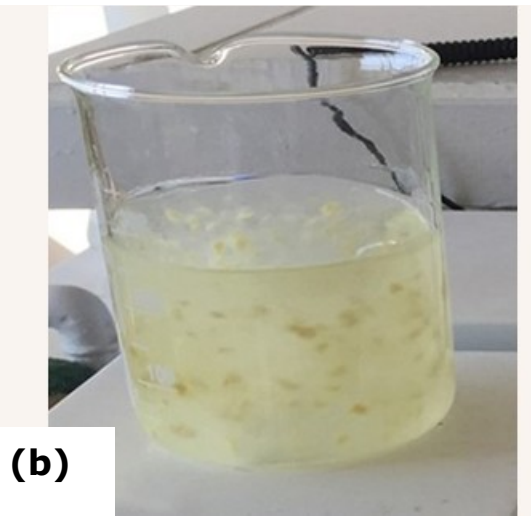

(b) bleached cellulose for the

\section{Production of Cellulose Nanocrystals}

The bleached cellulose was hydrolyzed with $\mathrm{H}_{2} \mathrm{SO}_{4}$, where, cellulose nanogel was obtained. Cellulose nanocrystals are produced from cellulose nanogel via the steps of cold-water precipitation, centrifugation, filtration, sonication, and drying.

\section{Hydrolysis}

The effect of three main parameters that affect the hydrolysis efficiency such as concentration of $\mathrm{H}_{2} \mathrm{SO}_{4}$, temperature, and hydrolysis time were examined. The ratio of the bleached cellulose and aqueous $\mathrm{H}_{2} \mathrm{SO}_{4}$ solution was kept constant at 1:100 where the concentration of $\mathrm{H}_{2} \mathrm{SO}_{4}$ was changed to 10,20 , 25,30 , and $40 \%$ w. $\mathrm{H}_{2} \mathrm{SO}_{4}$ was added to the cellulose-water mixture drop by drop on the magnetic stirrer at $1000 \mathrm{rpm}$ placed in a cold-water bath (at $4{ }^{\circ} \mathrm{C}$ ) in order to eliminate the burning of the cellulose because of the exothermic reaction between $\mathrm{H}_{2} \mathrm{SO}_{4}$ and $\mathrm{H}_{2} \mathrm{O}$. In order to achieve the highest hydrolysis efficiency, three different temperatures of 30,40 , and $50{ }^{\circ} \mathrm{C}$ and three different hydrolysis times of 30,45, and 60 minutes were investigated at constant $\mathrm{H}_{2} \mathrm{SO}_{4}$ concentration.
Cold water precipitation and centrifugation

At the end of the hydrolysis process, in order to finish the hydrolysis reaction, the hydrolyzed cellulose must be quenched with $100 \mathrm{~mL}$ of cold distilled water at $4{ }^{\circ} \mathrm{C}$. For removing any colloidal impurities from hydrolyzed cellulose, a centrifugation step was carried out twice at 5000 $\mathrm{rpm}$ for $15 \mathrm{~min}$.

\section{Filtration}

In order to remove remaining acids and salts from the hydrolyzed cellulose, a filtration step was carried out. The centrifuged cellulose was filtered and washed with distilled water until a neutral $\mathrm{pH}$ was reached after 7 days. $100 \mathrm{~mL}$ of distilled water was added to the filtered and dried cellulose.

\section{Sonication}

A Bandelin Sonopuls ultrasonic homogenizer equipped with $3 \mathrm{~mm}$ probe at a power of $70 \mathrm{~W}$ and amplitude of $30 \%$ for 10 minutes was used in the ice bath for avoiding agglomeration (3). The cellulose nanocrystal suspension resulting from this process was stored at $4{ }^{\circ} \mathrm{C}$ for further analysis. After sonication, the samples were dried in a closed 
air-circulating oven at $40{ }^{\circ} \mathrm{C}$ and the resulting products are shown in Figure 8.

\section{Characterization Methods}

Color determination values for the calculation of the whiteness indices of the samples were determined using a Hunterlab ColorFlex CFLX-45-2 (Reston, USA). After adjusting the $\mathrm{H}_{2} \mathrm{SO}_{4}$ concentration to an optimum value depending on the color measurement values, the effects of temperature and time on hydrolysis efficiency were investigated by further characterization methods. The functional groups of the samples were obtained by Fourier Transform Infrared spectra (FTIR) using $\mathrm{KBr}$ pellets with a Perkin Elmer Spectrum 100 Model in 650$4000 \mathrm{~cm}^{-1}$ spectral range with a resolution of $4 \mathrm{~cm}^{-1}$ at room temperature. X-ray Diffraction (XRD) analysis was conducted to identify the crystallographic structures of samples by Rigaku Smartlab Diffractometer. Thermal stability behavior (TGA) was investigated at atmospheric pressure using a TA Instrument SDT Q600. The morphology and dimension analyses of the different cellulose nanocrystals were investigated with an AFM method using a BRUKER Dimension Edge with Scan Asyst atomic force microscope at peak force tapping mod on an area of $20 \times 20 \mu \mathrm{m}$. A detailed morphological characterization was carried out by a Thermo Fischer Scientific Apreo scanning electron microscope (SEM). Prior to analysis, samples which were sonicated and coated on glass lamella were sputter-coated with gold/platinum using a vacuum plasma spray under argon atmosphere.

\section{Whiteness index calculation}

One of the several numerical indices was used to indicate the whiteness index (WI), which is an important output to proceed with the most effective $\mathrm{H}_{2} \mathrm{SO}_{4}$ concentration, as in Eq. (1) (16):

$$
W I=100-\left[(100-L)^{2}+\left(a^{2}+b^{2}\right)\right]^{1 / 2}
$$

where $L, a$, and $b$ refer to coordinates in Hunter's $L$, $a$, and $b$ Color Difference Equation.

\section{Yield calculation}

Before hydrolysis, the bleached celluloses was firstly weighed and recorded. Then the resulting cellulose nanocrystal product obtained after sonication and drying were weighed and recorded. The yield, which is an important output to determine the optimum temperature and time, was calculated as in Eq. (2) (17):
Yield $=\frac{\mathrm{m}_{1}}{\mathrm{~m}_{2}} \times 100 \%$

where $m_{1}$ is the mass of the cellulose nanocrystals obtained after sonication and drying and $\mathrm{m}_{2}$ is the mass of the bleached cellulose before hydrolysis.

\section{Crystallinity index calculation}

The crystallinity index was calculated from the $X-$ Ray diffraction patterns obtained over the range of $2 \theta=5-70^{\circ}$. From the XRD patterns, the crystallinity index (CrI) of samples was calculated based on the intensity between (200) and (101) lattice diffraction peaks by using following Eq. (3) (18):

$$
C r I=\left[\frac{\left(I_{200}-I_{a m}\right)}{I_{200}}\right] \times 100 \%
$$

where $I_{200}$ represents both crystalline and amorphous region of cellulose (maximum intensity at $2 \theta=22.5^{\circ}$ ) and $I_{a m}$ represents only amorphous phase (intensity of diffraction at $2 \theta=16^{\circ}$ ).

\section{Data Analysis}

In terms of experimental design, the effects of two important factors, temperature within the limits of 30 to $50\left({ }^{\circ} \mathrm{C}, \mathrm{X}_{1}\right)$, and time within the limits of 30 to $60\left(\min , \mathrm{X}_{2}\right)$ on the hydrolysis yield were performed with the help of the face centered $(a=1)$ Central Composite Design (CCD) of the Response Surface Methodology (RSM) using Design Expert $\AA$ 12.0.1.0 software (Stat-Ease, Inc., Minnesota, USA, 2019). The central condition was defined as $40^{\circ} \mathrm{C}$, and $45 \mathrm{~min}$, then a unit scale was set as $10^{\circ} \mathrm{C}$ for temperature, and $15 \mathrm{~min}$ for time. Consequently, there were 13 base runs consisting of 4 cube points, 5 center points in cube, and 4 axial points. The yield was correlated with the independent operating variables and defined in terms of a second-order polynomial equation (Eq. (4)):

$$
\mathrm{Y}=\mathrm{a}_{0}+\sum \mathrm{a}_{\mathrm{i}} \mathrm{X}_{\mathrm{i}}+\sum \mathrm{a}_{\mathrm{ii}} \mathrm{X}_{\mathrm{i}}{ }^{2}+\sum \mathrm{a}_{\mathrm{ij}} \mathrm{X}_{\mathrm{i}} \mathrm{X}_{\mathrm{j}}
$$

where, $a_{0}, a_{i}, a_{i i}$, and $a_{i j}$ are constant, linear, quadratic, and interaction coefficients, whereas $X_{i}$, $X_{i}{ }^{2}$, and $X_{j}$ represent the linear, quadratic, and interaction effects of factors, respectively. At a $95 \%$ confidence interval, the model significance and suitability were determined using the analysis of variance (ANOVA). 


\section{Temperature $\left({ }^{\circ} \mathrm{C}\right)$}

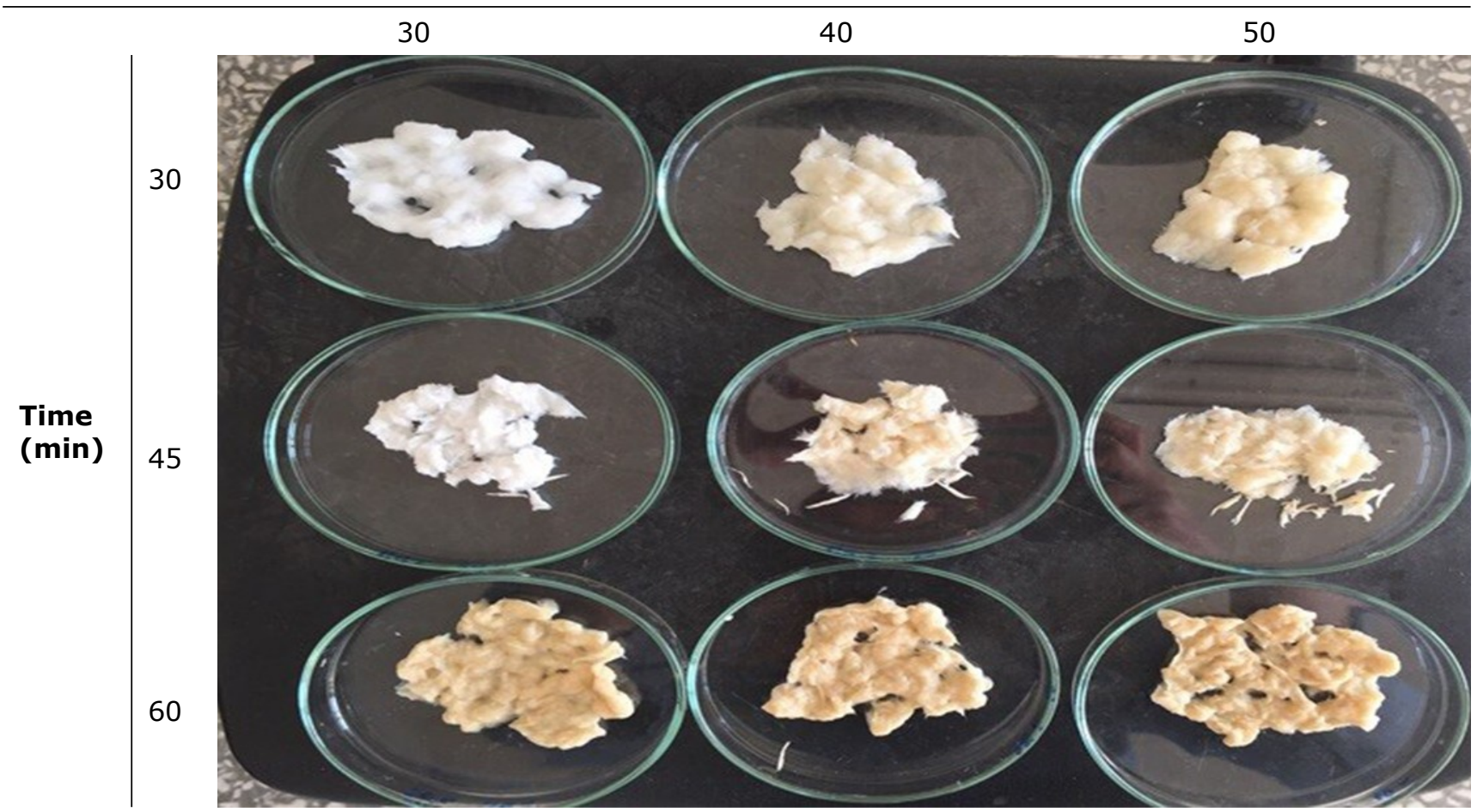

Figure 8: Resulting dried products after sonication at different temperatures and hydrolysis times.

\section{RESULTS AND DISCUSSION}

\section{Effect of $\mathrm{H}_{2} \mathrm{SO}_{4}$ Concentration on Hydrolysis Efficiency}

Paper fibers, still containing polyethylene and aluminum, must be treated with acetic acid solution for $100 \%$ separation (19). Thus, if an extra chemical treatment was performed via acetic acid solution, then it would cause additional cost during production. However, the main purpose of this study is to achieve suitable reaction conditions and to improve efficiency with lower cost. The amount of acid is the key factor for determining the costs and environmental impacts. The first stage of this investigation is the possibility of using a lower acid amount to produce cellulose nanocrystals. In order to determine the effect of acid concentration and identify a suitable concentration, five different concentrations of aqueous $\mathrm{H}_{2} \mathrm{SO}_{4}$ solutions were prepared such as $10,20,25,30$, and $40 \% \mathrm{w}$ at a constant temperature of $40{ }^{\circ} \mathrm{C}$ and time of $45 \mathrm{~min}$. Figure 9 (a)-(e) shows the effect of acid concentration on the color with the increasing amount of $\mathrm{H}_{2} \mathrm{SO}_{4}$. With the increasing amount of $\mathrm{H}_{2} \mathrm{SO}_{4}$ from Figure 9 (a) to (e), the decomposition of cellulose increases. On the other hand, excessive amount of $\mathrm{H}_{2} \mathrm{SO}_{4}$ causes the cellulose to become a dark color of cellulose as seen in Figure 9 (e) which is an undesired situation for cellulose nanocrystal quality.
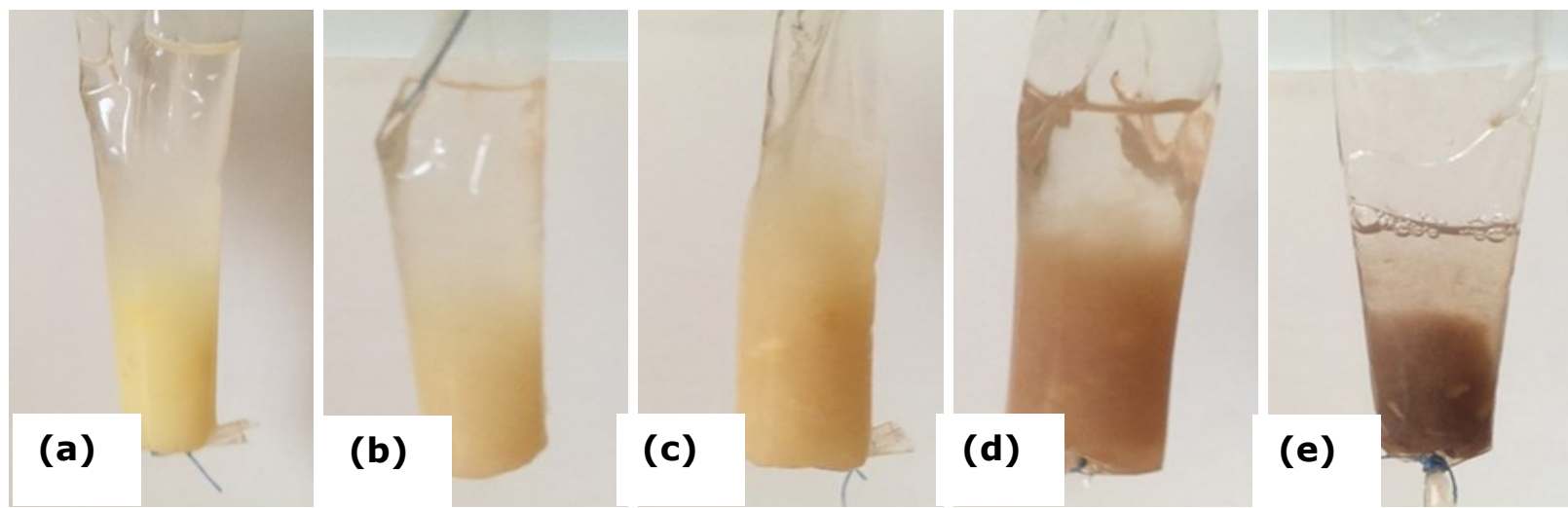

Figure 9: Cellulose samples after $\mathrm{H}_{2} \mathrm{SO}_{4}$ treatment with concentrations of (a) $10 \%$, (b) $20 \%$, (c) $25 \%$,

(d) $30 \%$, and (e) $40 \%$ by weight at $40{ }^{\circ} \mathrm{C}$ and $45 \mathrm{~min}$. 
Figure 10 shows the effect of acid concentration on the whiteness index (WI\%). The color of the hydrolyzed cellulose became darker with the increasing $\mathrm{H}_{2} \mathrm{SO}_{4}$ concentration as was proven previously in Figure 9. Until the $30 \% \mathrm{w}$ of $\mathrm{H}_{2} \mathrm{SO}_{4}$, the darkening occurred slowly and the cellulose nanocrystals had a relatively lighter color. At $30 \% \mathrm{w}$ of $\mathrm{H}_{2} \mathrm{SO}_{4}$, the color of cellulose nanocrystal turned into brown and after this concentration, i.e. at $40 \%$ w of $\mathrm{H}_{2} \mathrm{SO}_{4}$, the cellulose nanocrystal showed the darkest color. 25 wt\% of $\mathrm{H}_{2} \mathrm{SO}_{4}$ appeared to be the most acceptable concentration in terms of level of whiteness.

Compared to the studies in literature, $\mathrm{H}_{2} \mathrm{SO}_{4}$ concentration range appears to be in-between 50$72 \% \mathrm{w}$ (20) and the optimum concentration is determined to be $64 \% \mathrm{w}$ in most of the studies (21, 22). However, this value depends on the cellulose source. When the resource changes, the hydrolysis conditions also alter accordingly, where, in this study, the concentration of $\mathrm{H}_{2} \mathrm{SO}_{4}$ that was necessary for an effective hydrolysis reaction was found to be $25 \% \mathrm{w}$.

\section{Effect of Temperature and Time on Hydrolysis Efficiency}

The effect of temperature and time on hydrolysis efficiency was investigated at constant $\mathrm{H}_{2} \mathrm{SO}_{4}$ concentration of $25 \% \mathrm{w}$. The hydrolysis reaction performed at three different temperatures which were 30,40 , and $50{ }^{\circ} \mathrm{C}$ and for three different times which are 30,45 , and $60 \mathrm{~min}$.

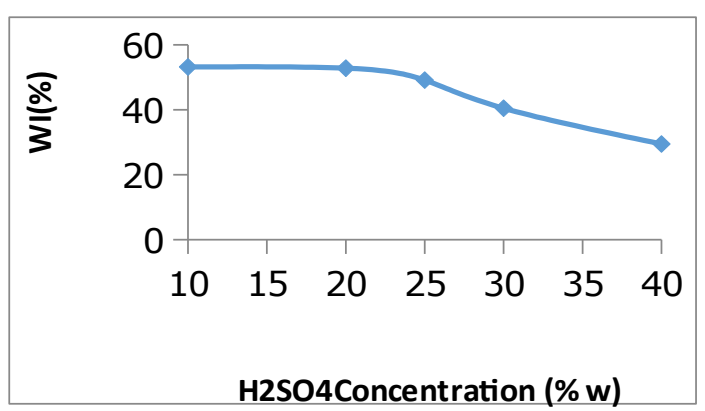

Figure 10: The effect of acid concentration on the whiteness index (WI\%).

\section{Whiteness index output}

After the color determination test, whiteness indexes of cellulose nanocrystals were calculated using $L, a$, and $b$ values which are given in Table 1 . The lightness values ( $L$ ) decrease with increasing temperature and time, whereas, the redness values (a) of the cellulose nanocrystals increase with increasing temperature and time. The yellowness values (b) increases slightly with increasing temperature and time. The change of color was evident for the darkening of cellulose nanocrystals at higher temperature and time. According to Table 1 , the whiteness index values decreases with the increasing amount of temperature and time, so, the color of the cellulose nanocrystals became darker. As expected, the highest white color was observed for the cellulose nanocrystal obtained at $30{ }^{\circ} \mathrm{C}$ for $30 \mathrm{~min}$ as $84.42 \%$ and the darkest color was observed for cellulose nanocrystal obtained at $50{ }^{\circ} \mathrm{C}$ for $60 \mathrm{~min}$ as $56.00 \%$.

Table 1: The whiteness index (\%) values due to varying temperature and time.

Temperature $\left({ }^{\circ} \mathrm{C}\right)$

\begin{tabular}{c|cccc}
\hline & & $\mathbf{3 0}$ & $\mathbf{4 0}$ & $\mathbf{5 0}$ \\
& $\mathbf{3 0}$ & 84.42 & 64.08 & 57.96 \\
Time & $\mathbf{4 5}$ & 73.55 & 67.68 & 67.23 \\
& $\mathbf{6 0}$ & 69.84 & 62.45 & 56.00 \\
\hline
\end{tabular}

\section{Yield optimization}

The yield of cellulose nanocrystals was calculated based on the samples after sonication and filtration in order to avoid the effect of the oversized particles from agglomeration and incomplete reaction. The yield results of the experimental base runs of uncoded values for the selected temperature, and time are tabulated in Table 2.
As it can be deduced from Table 2, that the highest and lowest yields were observed for cellulose nanocrystal obtained at $30{ }^{\circ} \mathrm{C}$ for $30 \mathrm{~min}$ as $61.20 \%$ and $50{ }^{\circ} \mathrm{C}$ for $60 \mathrm{~min}$ as $46.32 \%$, respectively. The binary effects of the two factors on the yield are depicted by the three- dimensional response surface, together with the contour plot in Figure 11 (a-b) 
Table 2: The yield (\%) values under different temperature, and time factors and their levels.

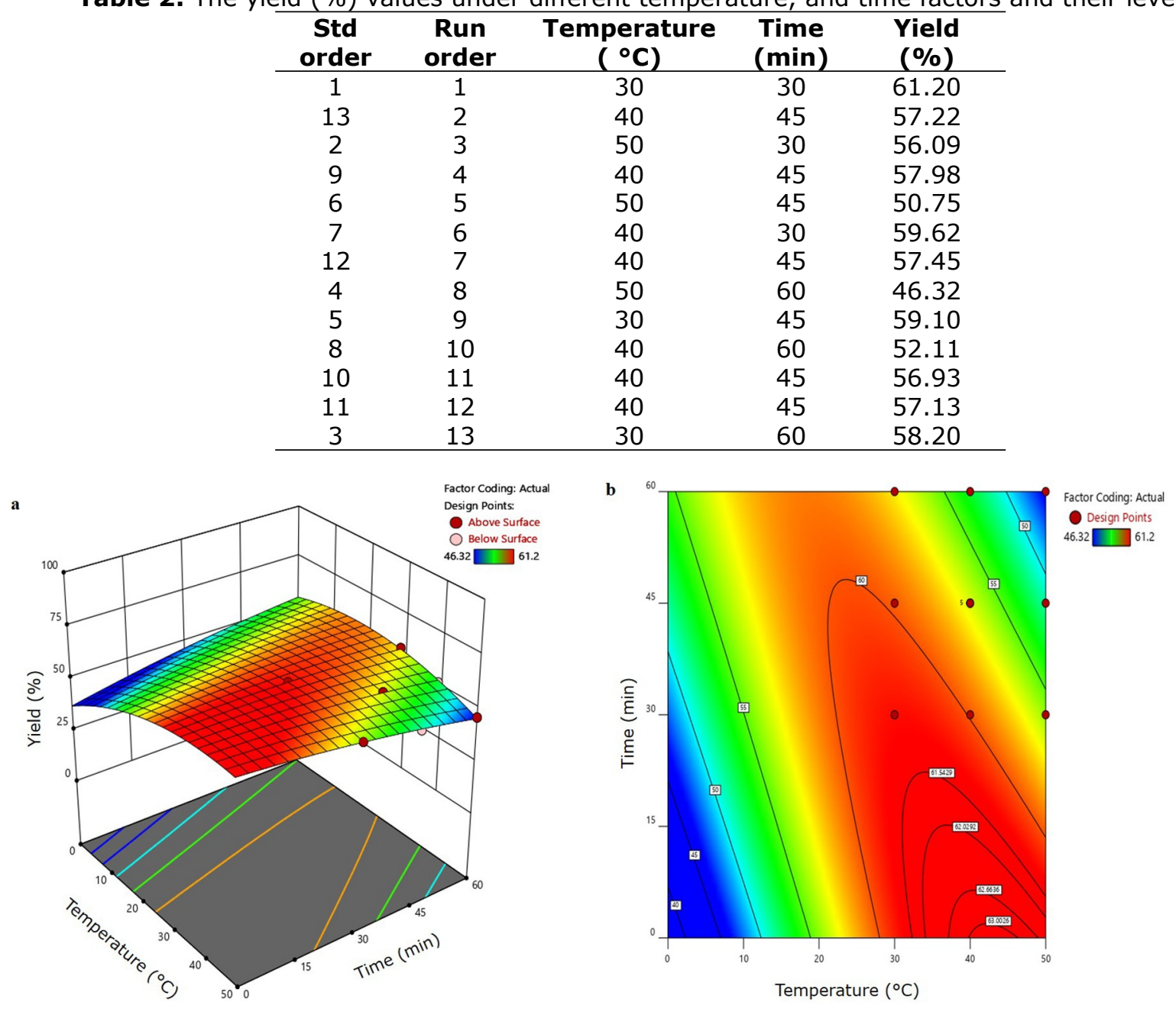

Figure 11: (a) The surface and (b) the counter plot of the yield with respect to the changes in the temperature $\left({ }^{\circ} \mathrm{C}\right)$, and time $(\mathrm{min})$.

As seen in Figure 11 (a), by decreasing or increasing the temperature and time simultaneously, the yield of cellulose nanocrystals deteriorated as Lu and Hsieh (2010) have found (23). These conditions form the endpoints of the curvature. The counter plot in Figure 11 (b) proves that the lowest yield values shown by the blue color were achieved at low-low and high-high temperature and time. The maximum yield was obtained at the condition where the temperature was high, and the time was the lowest. As referred in Diop and Lavoie (2017)'s study, the phenomenon about higher yield at lower time is related to the irregularity of the crystalline region (3).

As a result of the modelling studies, the secondorder polynomial equation of the yield (\%) as a function of temperature, and time was expressed as in Eq. (5):

$\mathrm{Y}=36.01609+1.24486 \times \mathrm{T}+0.429726 \times \mathrm{t}$ 
Table 3: ANOVA of the yield data for temperature, and time effects.

\begin{tabular}{|c|c|c|c|c|c|}
\hline Source & DF & Adj SS & Adj MS & F-value & P-value \\
\hline Model & 5 & 196.47 & 39.29 & 71.48 & 0 \\
\hline$T\left(X_{1}\right)$ & 1 & 107.02 & 107.02 & 194.67 & 0 \\
\hline$t\left(X_{2}\right)$ & 1 & 68.55 & 68.55 & 124.69 & 0 \\
\hline$T^{2}\left(X_{1}^{2}\right)$ & 1 & 5.80 & 5.80 & 10.55 & 0.0141 \\
\hline$t^{2}\left(X_{2}^{2}\right)$ & 1 & 0.72 & 0.72 & 1.30 & 0.2912 \\
\hline $\operatorname{Txt}\left(X_{1} X_{2}\right)$ & 1 & 11.46 & 11.46 & 20.84 & 0.0026 \\
\hline Residual & 7 & 3.85 & 0.55 & & \\
\hline Lack of Fit & 3 & 3.20 & 1.07 & 6.58 & 0.0501 \\
\hline Pure Error & 4 & 0.6483 & 0.16 & & \\
\hline Total & 12 & 200.31 & & & \\
\hline \multirow{2}{*}{ Fit Statistics } & Std. Dev. & $\mathbf{R}^{2}(\%)$ & $R^{2}$-adj (\%) & $\mathbf{R}^{2}$-pred (\%) & \\
\hline & 0.7414 & 98.08 & 96.71 & 87.92 & \\
\hline
\end{tabular}

In equation $5, T$ stands for temperature $\left({ }^{\circ} \mathrm{C}\right)$, and $t$ for time $(\mathrm{min})$. The analysis of variance for the proposed quadratic model is tabulated in Table 3. The model F-value of 71.48 and the lack of fit of the p-value of 0.05 presented in Table 3 implied that the model was significant and exhibited a good fit. All the terms of the model were significant due to $\mathrm{P}$ values being smaller than 0.05, except the quadratic term of time. Both from the F-value being the highest and $p$ value being the lowest, it is clear that the temperature is more effective factor on the yield compared to the time. The correlation coefficients, $\mathrm{R}^{2}, \mathrm{R}^{2}$-adj, and $\mathrm{R}^{2}$-pred being $98.08 \%$, $96.71 \%$, and $87.92 \%$, respectively could be attributed to the observed and the predicted value agreement (Table 3).

\section{FTIR analysis}

After the paper and polyethylene layers were separated appropriately from the Tetra Pak package, functional groups of alkaline-treated and bleached cellulose have been analyzed using FTIR spectroscopy (Figure 12).

From Figure 12, it can be observed that both alkaline-treated, and bleached cellulose showed peaks at 3345 and $2921 \mathrm{~cm}^{-1}$ which were attributed to aromatic and aliphatic $\mathrm{O}-\mathrm{H}$ stretching intramolecular hydrogen bonds for cellulose and to the $\mathrm{C}-\mathrm{H}$ stretching vibrations of the methyl group respectively (24). For the alkaline-treated cellulose two peaks were encountered at 1516 and $1590 \mathrm{~cm}^{-}$ 1 , but not observed for bleached cellulose because these peaks were related to the $\mathrm{O}-\mathrm{H}$ bending in water and $\mathrm{C}=\mathrm{C}$ stretching vibration of the aromatic ring in the residual lignin (25) which can be clearly seen in the magnified FTIR spectra in Figure 13. The peaks which were observed at wave numbers of 1436 and $1321 \mathrm{~cm}^{-1}$ were related to respectively the $\mathrm{CH}_{2}$ bending vibration in cellulose and the $\mathrm{CH}_{2}$ rocking vibration. These two peaks were attributed to cellulose, hence they both existed in the alkalinetreated and bleached cellulose. However, the peak at $1280 \mathrm{~cm}^{-1}$ was not observed in the bleached cellulose since this peak was related to the $\mathrm{C}-\mathrm{O}-\mathrm{H}$ stretching at $\mathrm{C}_{6}$ which was attributed to lignin and xylan content $(26,27)$. The peaks appeared at the wave numbers of 1197,1035 , and $903 \mathrm{~cm}^{-1}$ were related to $\mathrm{C}-\mathrm{O}-\mathrm{C}$ symmetric stretching and $\mathrm{OH}$ plane deformation, $\mathrm{C}-\mathrm{O}-\mathrm{C}$ pyranose ring stretching vibration, and the cellulosic $\beta$-glycosidic linkages, respectively $(26,27)$. When the alkaline-treated and bleached cellulose were compared, this observation could corroborate that the alkaline treatment and bleaching process had successfully reduced most of the impurities, especially its lignin content.

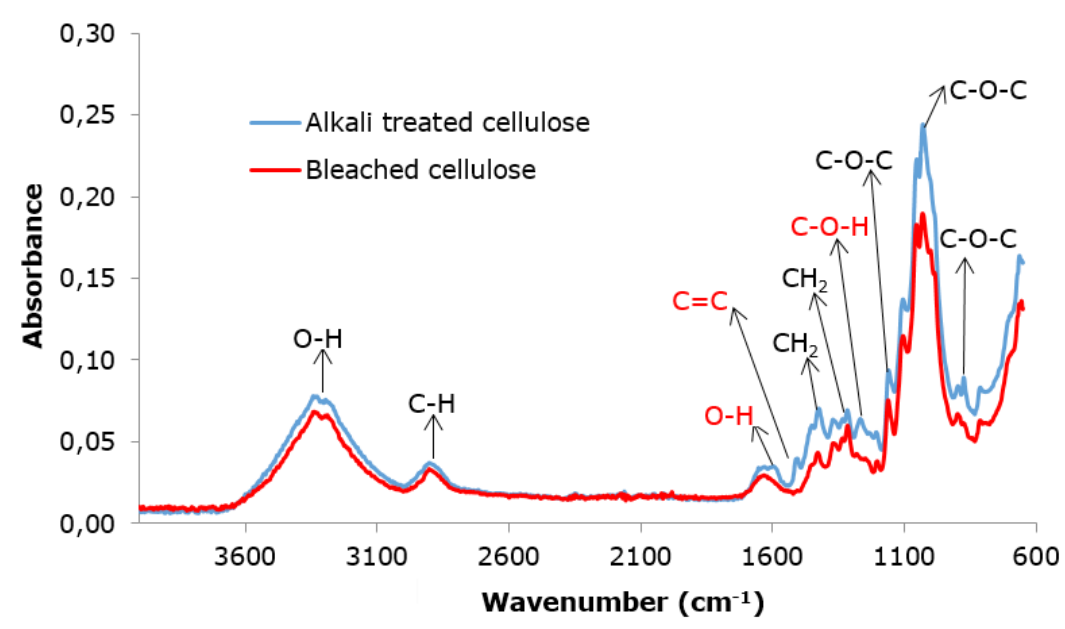

Figure 12: FTIR spectra of alkaline-treated and bleached cellulose. 


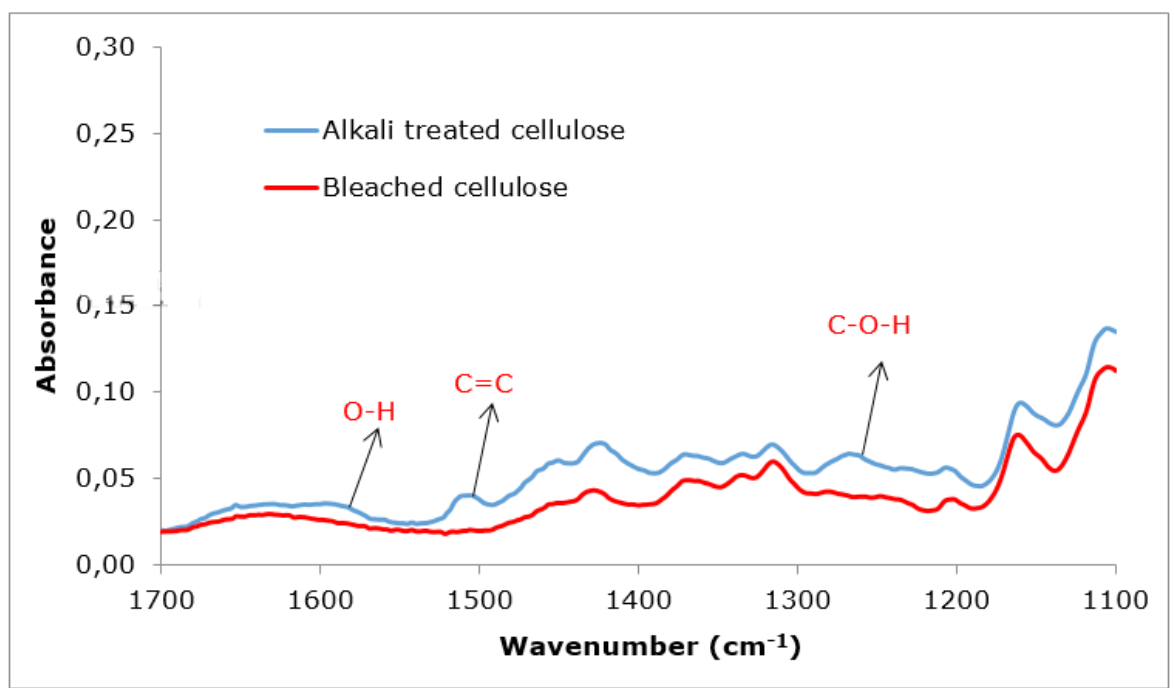

Figure 13: Magnified FTIR spectra of alkaline-treated and bleached cellulose revealing the vibration between 1700 and $1100 \mathrm{~cm}^{-1}$.

Figure 14 represents FTIR spectra of CNCs produced at different temperatures and times in comparison with commercial microcrystalline cellulose. According to Figure 14, at 3345, 2921, 1516, 1590, $1436,1321,1197,1035$, and $903 \mathrm{~cm}^{-1}$, the same peaks appeared for all samples. All characteristic peaks of cellulose were observed similarly for the CNCs obtained at nine conditions. Comparing Figure 12 and 14, it is seen that the CNCs have the same peaks like bleached cellulose. Unlike alkaline-treated cellulose, the peaks were not observed at the wave numbers of 1590,1516 , and $1280 \mathrm{~cm}^{-1}$. So, with the acid hydrolysis process, any kind of change does not occur in the structure of the bleached cellulose.

\section{$X R D$ analysis}

XRD analyses of the cellulose nanocrystal samples produced at different temperature and time in comparison with the alkaline-treated cellulose were performed (28) as seen in Figure 15.

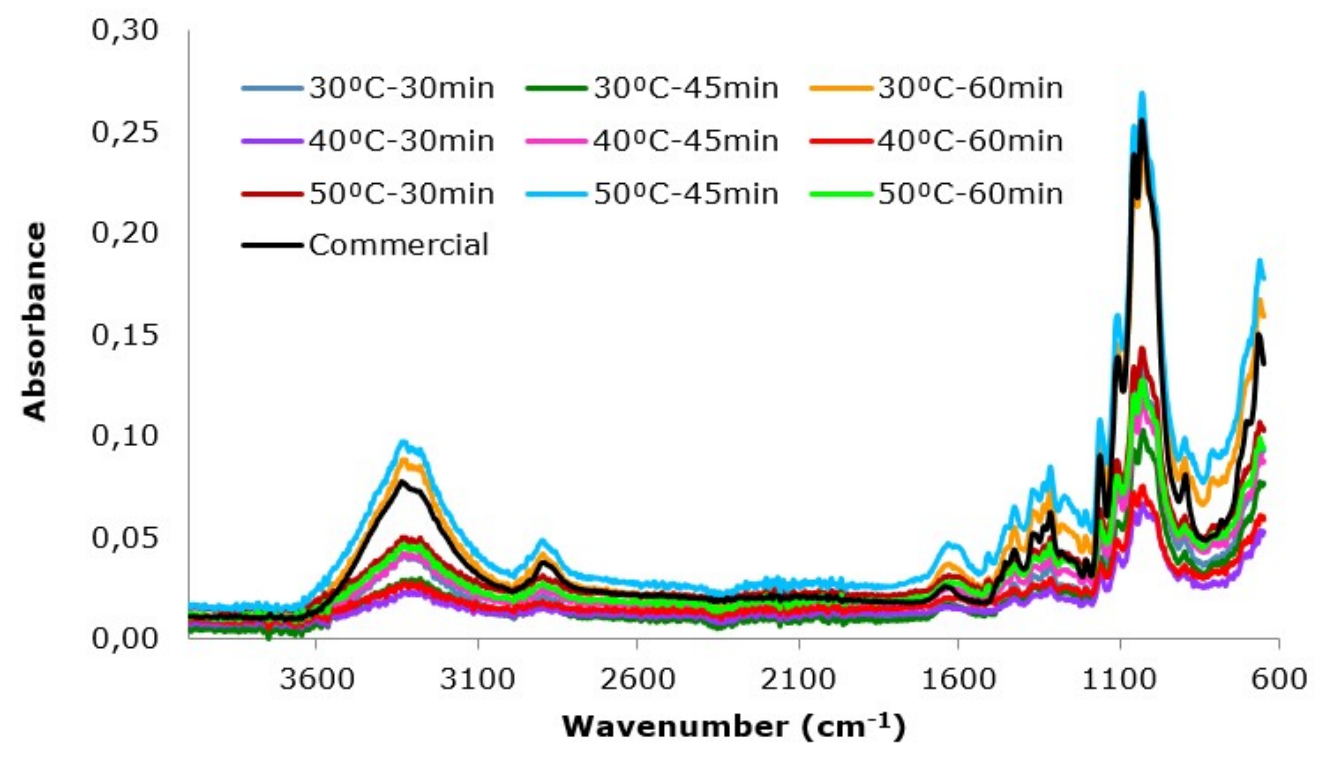

Figure 14: FTIR spectra of cellulose nanocrystals produced at different temperatures and times. 


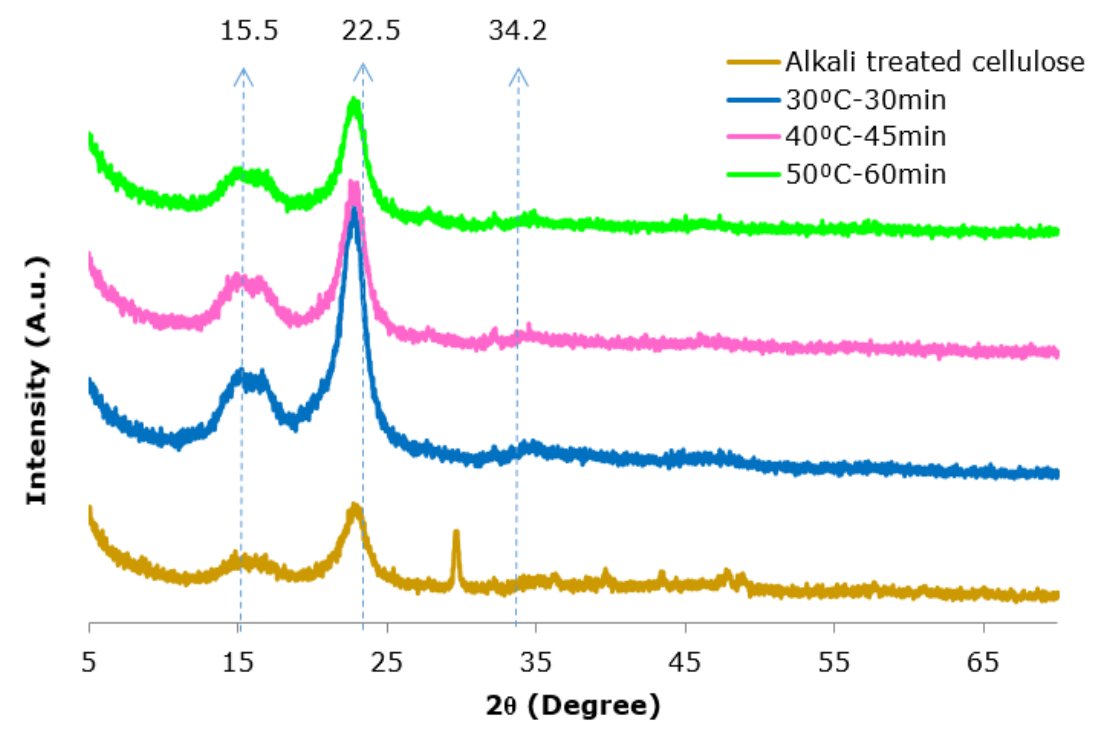

Figure 15: XRD patterns of the alkaline-treated cellulose and cellulose nanocrystals produced at different temperatures and times.

According to Figure 15, the XRD patterns of alkaline-treated cellulose and cellulose nanocrystals showed similar peaks at three different planes which are $2 \theta=15.5$ (plane 110), $2 \theta=22.5$ (plane 200), and $2 \theta=34.2$ (plane 004) which are the characteristic peaks of the cellulose I crystalline structure (29, 30). This observation was suggested that the crystalline structure of cellulose I remained even after alkali and acid hydrolysis treatments $(31,32)$. At two peak points, the alkaline-treated cellulose slightly differed from the cellulose nanocrystals. At the first point, around $15.5^{\circ}$, two peaks were observed for the cellulose nanocrystals and only one peak was observed for the alkaline-treated cellulose which was attributed to higher crystallinity (33). At the second point, peaks at $15.5^{\circ}, 22.5^{\circ}$, and $34.2^{\circ}$, were more intensified for the cellulose nanocrystals according to the alkaline-treated cellulose. During acidic hydrolysis, hemicellulose and lignin were dissolved and the remaining crystalline cellulose part was isolated. These particles caused intense and sharp peaks because of efficiently removing the amorphous parts (33) meaning that with acidic hydrolysis, most of amorphous parts were removed and crystallinity was increased.

The variation of the crystallinity index values calculated by Eq. (3) for the alkaline-treated cellulose and cellulose nanocrystals is shown in Figure 16 . The crystallinity index values of all the cellulose nanocrystals were greater than that of the alkaline-treated cellulose. The reason for this is the residual lignin and hemicellulose content after the alkali treatment and bleaching procedure, the crystallinity index slightly increased because of removing most of the impurities (33). According to Figure 16, the crystallinity index values of cellulose nanocrystals were found as 72,71 , and $69 \%$ for 30 ${ }^{\circ} \mathrm{C}$ for $30 \mathrm{~min}, 40{ }^{\circ} \mathrm{C}$ for $45 \mathrm{~min}$, and $50{ }^{\circ} \mathrm{C}$ for 60 min, respectively which are very close to each other. Similar behavior was observed by dos Santos et al. (2013) and Nascimento et al. (2018) (21,34). Another parameter affecting the crystallinity index is particle size. Shorter particles foster a better surface contact with the hydrolytic solution and result in a more efficient access to the intercrystalline regions. So, the crystallinity index tends to extent. Hence, the reason for the lower crystallinity index could be attributed to the larger particle size.

\section{TGA analysis}

The thermal stability behaviors of the cellulose nanocrystal samples produced at different temperature and time in comparison with the alkaline-treated cellulose are shown in Figure 17. 


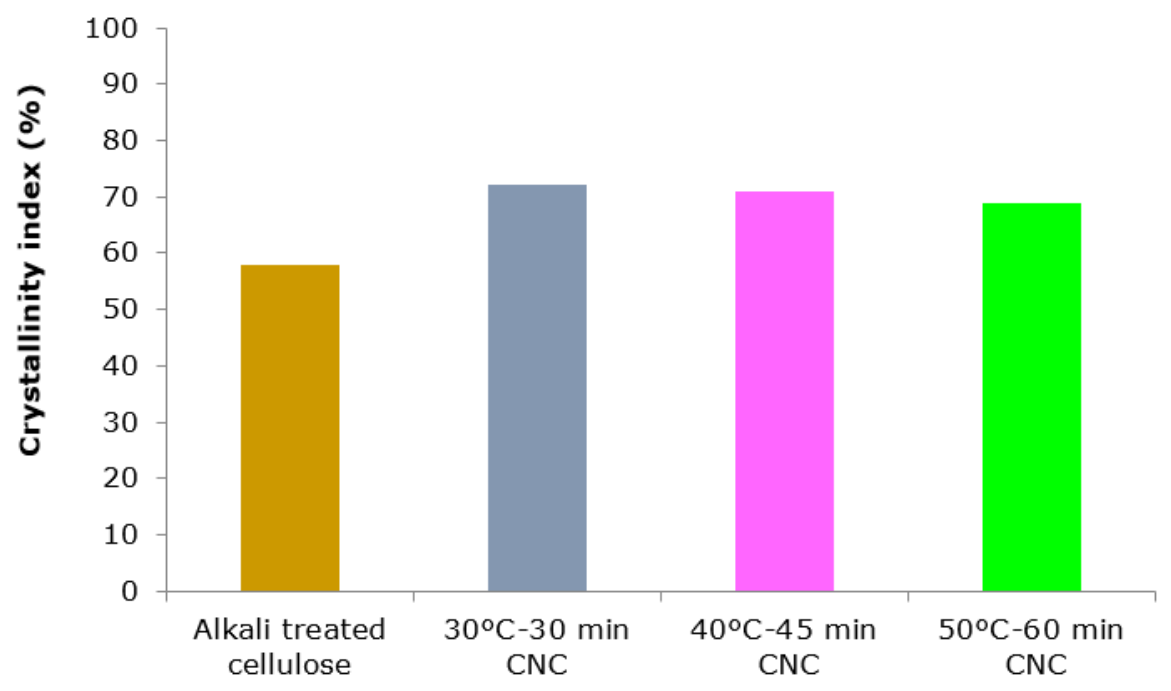

Figure 16: The crystallinity index values of the alkaline-treated cellulose and cellulose nanocrystals produced at different temperatures and times.

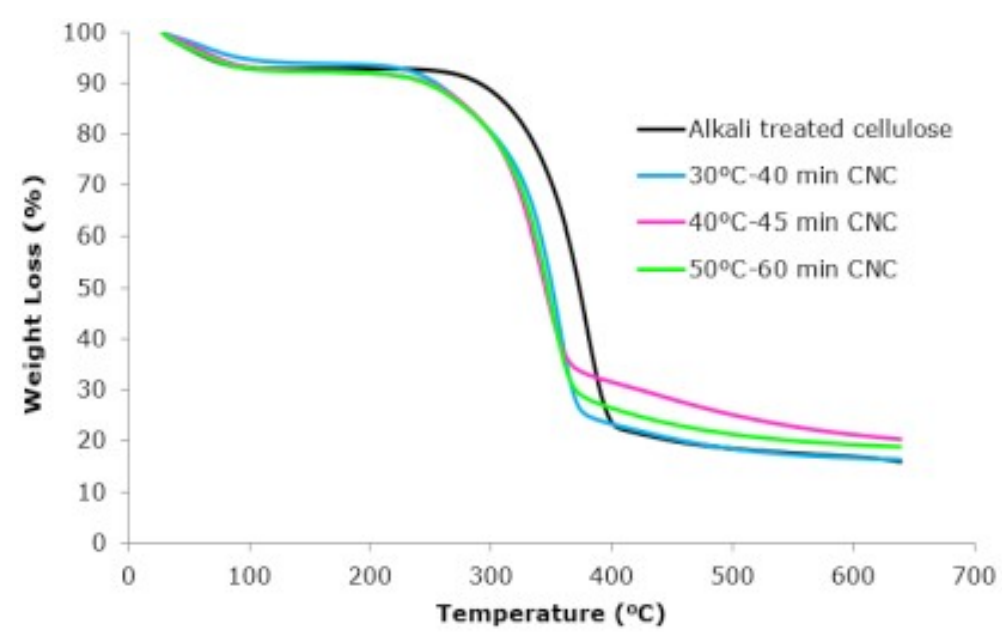

Figure 17: TGA curves of alkaline-treated cellulose and cellulose nanocrystals produced at different temperatures and times.

In Figure 17, two degradation phases and small mass losses $(<10 \%)$ were detected for all samples, which corresponded to the evaporation of water from the surface of the samples $(21,35,36)$. The first degradation was observed around $100^{\circ} \mathrm{C}$ and the temperature range between 100 and $200{ }^{\circ} \mathrm{C}$ is a signal of the depolymerization of non-cellulosic components such as hemicellulose revealing the breakage of the glycosidic bonds. The second degradation peaks were observed at 354,345 and $352{ }^{\circ} \mathrm{C}$ for CNCs produced at $30^{\circ} \mathrm{C}$ for $30 \mathrm{~min}, 40$ ${ }^{\circ} \mathrm{C}$ for $45 \mathrm{~min}$, and $50{ }^{\circ} \mathrm{C}$ for $60 \mathrm{~min}$, respectively showing the degradation of the a-cellulose $(37,38)$. The degradation temperature for all of the cellulose nanocrystals were nearly the same. Besides, mass losses for the cellulose nanocrystals were also almost identical (65\%). So, the degradation temperature of CNCs did not vary significantly with respect to the hydrolysis temperature and time. Also the thermogram of $30^{\circ} \mathrm{C}$ for 30 min $\mathrm{CNC}$ has a small peak at $279^{\circ} \mathrm{C}$ corresponding to hemicellulose decomposition (27). This shows that the hemicellulose was not exactly removed from $30^{\circ} \mathrm{C}$ for 30 min CNC, however exactly removed from 40 ${ }^{\circ} \mathrm{C}$ for $45 \mathrm{~min}$, and $50{ }^{\circ} \mathrm{C}$ for $60 \mathrm{~min} \mathrm{CNC}$.

The thermal degradation for three of CNCs started at nearly $220^{\circ} \mathrm{C}$, while for the alkaline-treated cellulose degradation began at nearly $290{ }^{\circ} \mathrm{C}$. The replacement of hydroxyl groups by acid sulfate (O$\mathrm{SO}_{3} \mathrm{H}$ ) groups in the hydrolysis step decreased the activation energy for the degradation of CNCs, making the sample less resistant to the pyrolysis. Therefore, the dehydration reactions occurred leading to the release of water and catalyzed nanocrystal decomposition (33).

AFM analysis and dimension measurement

The 3D AFM images of the cellulose nanocrystals obtained at various temperature and time are 
shown in Figure 18, where, the bright and dark regions represented the crystalline areas and the amorphous portions in the direction of the fiber axis in the cellulose structure, respectively (39). As the temperature increased from $30^{\circ} \mathrm{C}$ to $50{ }^{\circ} \mathrm{C}$ and time increased from $30 \mathrm{~min}$ to $60 \mathrm{~min}$, the brighter regions occupied larger area than the darker regions meaning that the cellulose consisted both amorphous and crystalline parts and with the increment in temperature and time, the crystalline regions were enhanced while amorphous regions were reduced as expected. Moreover, rod-shaped nanoparticles with individual nanocrystals and some aggregates of the cellulose fibers could be observed from Figure 18 . During the process of acidic hydrolysis, the amorphous parts of cellulosic fibers were transversely cleaved, while the straight crystalline parts intact remained. Consequently, the sizes of the fibers were reduced. The aggregates were probably corresponded to the high specific area and strong hydrogen bonds existing in cellulose. Therefore, the bundles of cellulose nanocrystals fabricated larger dimensions (40).

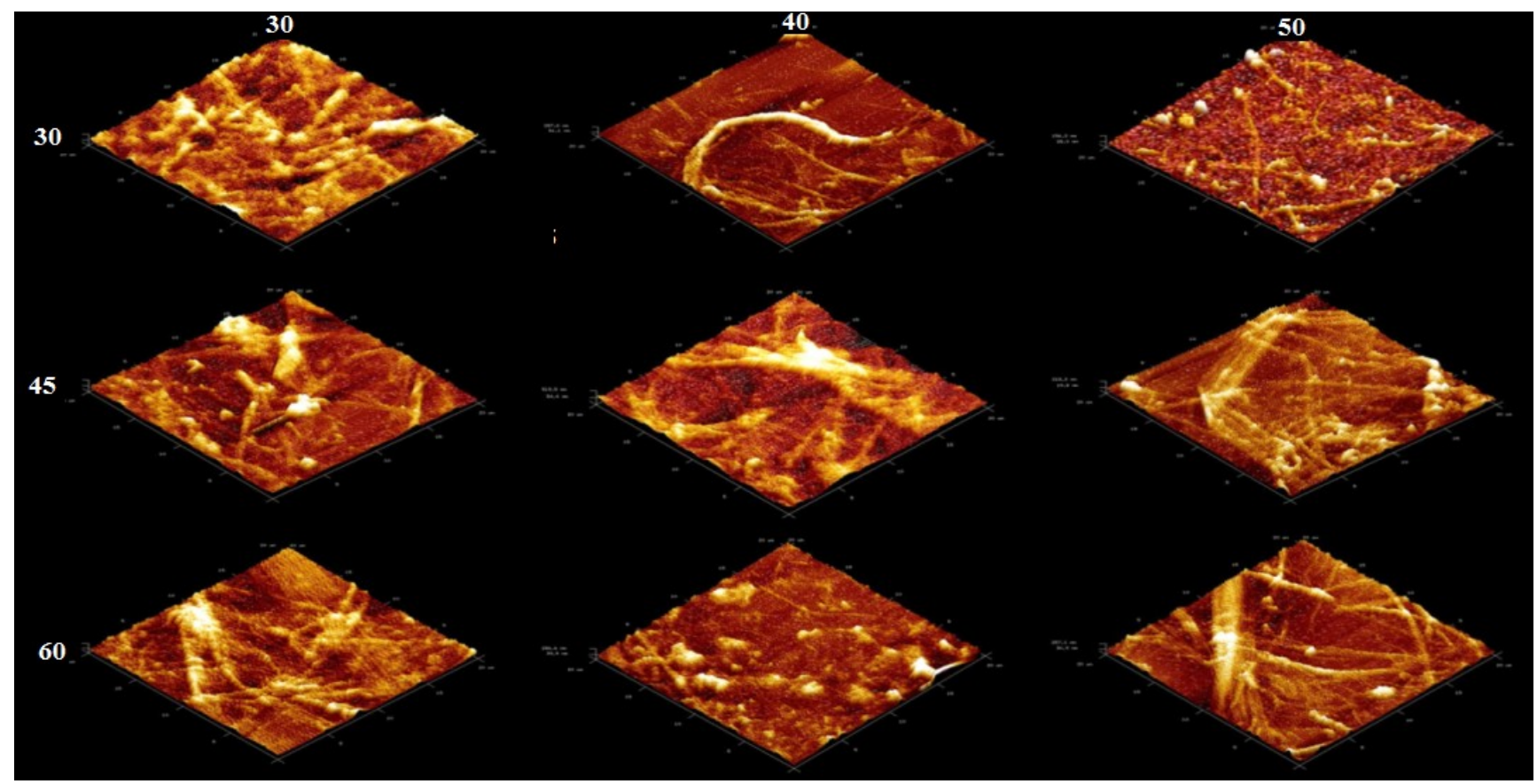

Figure 18: The 3D AFM images of CNCs produced at various temperatures $\left({ }^{\circ} \mathrm{C}, \mathrm{x}\right.$ axis) and times (minutes, y axis).

The diameters of the cellulose nanocrystals produced at different temperature and time were tabulated in Table 4. The diameters of the cellulose nanocrystals were reduced with the increasing temperature and time as expected $(22,34)$. The highest diameter value was measured as $403 \mathrm{~nm}$ at $30{ }^{\circ} \mathrm{C}$ for $30 \mathrm{~min} \mathrm{CNC}$, and conversely, the lowest diameter value was measured as $175 \mathrm{~nm}$ at $50{ }^{\circ} \mathrm{C}$ for 60 min CNC.

Table 4: The diameters ( $\mathrm{nm}$ ) of CNCs due to varying temperature and time.

\begin{tabular}{llccc}
\hline & & \multicolumn{3}{c}{ Temperature $\left({ }^{\circ} \mathbf{C}\right)$} \\
& & $\mathbf{3 0}$ & $\mathbf{4 0}$ & $\mathbf{5 0}$ \\
\hline \multirow{2}{*}{ Time } & $\mathbf{3 0}$ & 403 & 314 & 205 \\
(min) & $\mathbf{4 5}$ & 319 & 314 & 189 \\
& $\mathbf{6 0}$ & 306 & $306-314$ & 175 \\
\hline
\end{tabular}



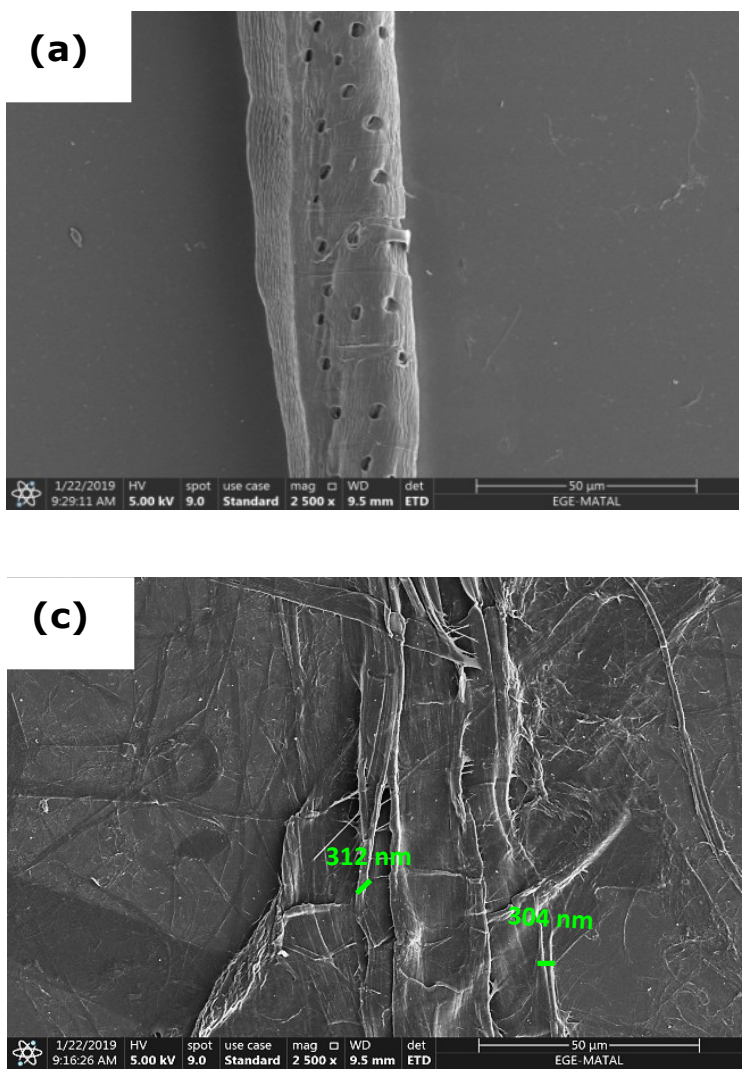
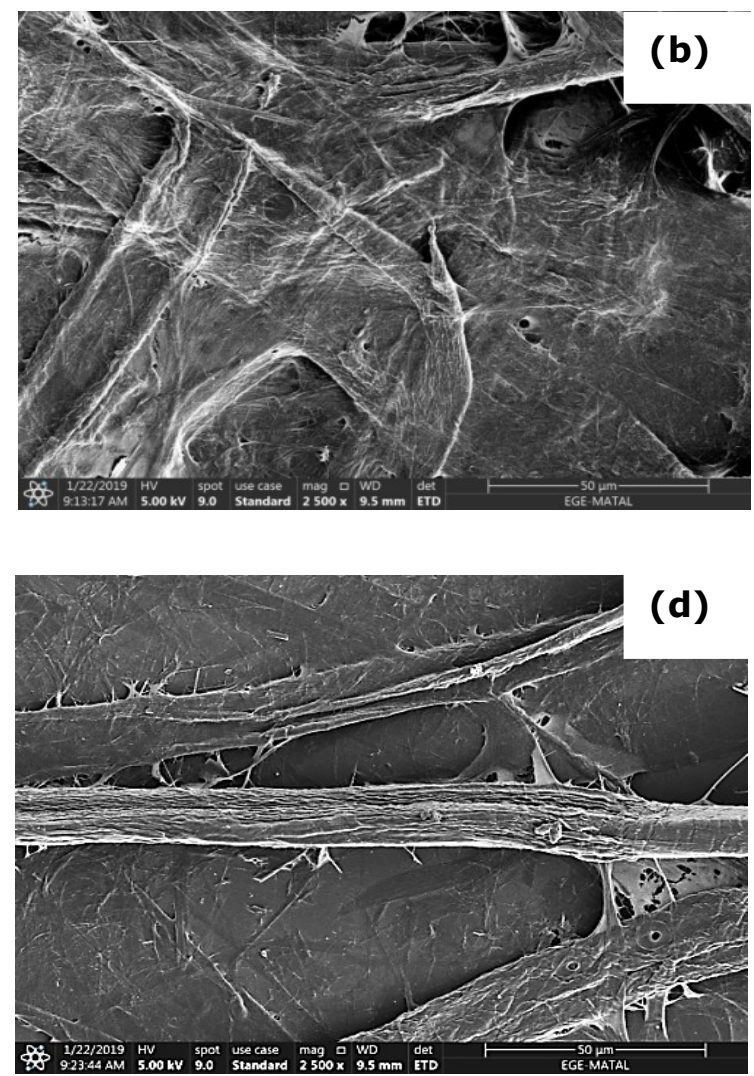

Figure 19: SEM images of (a) alkaline-treated cellulose, and the cellulose nanocrystals produced at (b) 30 ${ }^{\circ} \mathrm{C}-30 \mathrm{~min}$, (c) $40^{\circ} \mathrm{C}-45 \mathrm{~min}$, and (d) $50{ }^{\circ} \mathrm{C}-60 \mathrm{~min}$.

The dimensions of nanocellulose depend strongly on the processing techniques. $\mathrm{H}_{2} \mathrm{SO}_{4}$ hydrolysis usually could cleave the amorphous parts of cellulose fibers transversely, resulting in the diameter reduction of fibers (41). Another factor that affects the diameter of cellulose nanocrystal is the starting source of the cellulose. In the literature, the approximate diameters for most of the cellulose nanocrystals obtained from different sources like arecanut husk, bamboo, beer residue and elephant grass were found to be in the range of $1-10,50-100,146-173$, and $8-5 \mathrm{~nm}$ respectively $(42,43,34)$. The measured diameters from the AFM images of the cellulose nanocrystals were larger than the actual values due to the severe tip broadening effect in AFM measurements. Aggregation and overlapping of the individual fibers made it difficult to determine the accurate size and aspect ratios of the CNCs.

\section{SEM Analysis}

The detailed morphological structures of the alkaline-treated and cellulose nanocrystals produced at different temperature and time $\left(30^{\circ} \mathrm{C}-30 \mathrm{~min}, 40\right.$ ${ }^{\circ} \mathrm{C}-45 \mathrm{~min}$, and $50{ }^{\circ} \mathrm{C}-60 \mathrm{~min}$ ) were investigated by SEM images taken at $50 \mu \mathrm{m}$ in Figure 19 (a-d), respectively. The rod-shaped cellulose nanocrystals were examined in all of the images $(33,44)$. In Figure 19 (a), it is seen that the alkaline-treated cellulose had a smoother surface without flakes, but there existed still small dots on fibers that might be because of the hemicellulose and lignin content. According to Figure 19 (b), the cellulose nanocrystal obtained at $30^{\circ} \mathrm{C}$ for $30 \mathrm{~min}$ had aggregation and its fibers were long and tortuous. With the increment in temperature and time based on Figure 19 (c) and (d), the surface of cellulose nanocrystals became smoother, the complexity of the structure and aggregation on the surface decreased. Besides that, the diameters of the cellulose nanocrystals reduced and the fibers were much more individually distributed and aligned.

\section{CONCLUSION}

In this study, a potentially viable recycling route was followed to produce cellulose nanocrystals, which have wide application areas and an ecofriendly nature, from multilayered recycled aseptic Tetra Pak waste food packages by the acid hydrolysis method with $\mathrm{H}_{2} \mathrm{SO}_{4}$ after a series of alkali treatment and bleaching processes. The effects of temperature of 30,40 , and $50^{\circ} \mathrm{C}$ and time of 30 , 45 , and $60 \mathrm{~min}$ on the hydrolysis efficiency were investigated. At the optimum $\mathrm{H}_{2} \mathrm{SO}_{4}$ concentration of $25 \% \mathrm{w}$, the whiteness index was measured as $49.13 \%$, after this point, this value rapidly decreases. The whiteness index of the cellulose nanocrystals at $30^{\circ} \mathrm{C}$ for 30 min was $84.42 \%$, while it was $56.00 \%$ at $50{ }^{\circ} \mathrm{C}$ for 60 min showing that the whiteness index decreased with respect to an 
increase in temperature and time. Optimization studies using the experimental design carried out for the yield showed that the maximum yield was obtained at the condition where the temperature was high and the time was the lowest.

The FTIR spectra of the cellulose nanocrystal obtained at different temperatures and times were nearly the same with each other and showed similarity with the bleached cellulose. The XRD patterns of cellulose nanocrystals showed that with the acidic hydrolysis, the amorphous parts were removed and crystallinity was increased. The crystallinity index of alkaline-treated cellulose was much lower than those of the cellulose nanocrystals. From TGA graph, it was seen that the degradation temperatures of all cellulose nanocrystals were nearly the same and lower than the alkaline-treated cellulose. With respect to AFM results, it was concluded that as the temperature and time increased, the diameters of the cellulose nanocrystals were reduced. The lowest diameter value was measured as $175 \mathrm{~nm}$ at $50{ }^{\circ} \mathrm{C}$ for $60 \mathrm{~min}$ CNC, whereas, on the other hand, the highest diameter value was measured as $403 \mathrm{~nm}$ at $30{ }^{\circ} \mathrm{C}$ for $30 \mathrm{~min}$ CNC. SEM micrographs also confirmed that the surface of cellulose nanocrystals became smoother, the diameters of the cellulose nanocrystals reduced and the fibers were much more individually distributed with the increment in temperature and time.

\section{CONFLICT OF INTEREST}

The authors declare that they have no known competing financial interests or personal relationships that could have appeared to influence the work reported in this paper.

\section{ACKNOWLEDGMENTS}

The authors would like to express their heartiest gratitude and sincere thanks to Prof. Dr. Serap CESUR (Ege University) for her support and guidance.

\section{REFERENCES}

1. Szabó AM, Koltai L, Fodor L. Comparative analysis of aluminium and aluminium free recycled multilayered beverage carton packaging. J Graph Eng Des. 2013;42:13-9.

2. Baskoro Lokahita, Muhammad Aziz, Yoshikawa K, Takahashi F. Energy and resource recovery from Tetra Pak waste using hydrothermal treatment. Applied Energy. 2017 Dec;207:107-13. <DOI $>$.

3. Diop CIK, Lavoie J-M. Isolation of Nanocrystalline Cellulose: A Technological Route for Valorizing Recycled Tetra Pak Aseptic Multilayered Food Packaging Wastes. Waste Biomass Valor. 2017 Jan;8(1):41-56. <DOI>.
4. Anonymous. Tetra Pak. Sustainability Report 2021 [Internet]. Tetra Pak; 2021. Available from: https://www.tetrapak.com/content/dam/tetrapak/publicwe b/gb/en/sustainability/

TetraPak Sustainability Report 2021

5. Yilgor N, Köse C, Terzi E, Figen AK, Ibach R, Kartal SN, et al. Degradation Behavior and Accelerated Weathering of Composite Boards Produced from Waste Tetra Pak® Packaging Materials. BioResources. 2014 Jun 25;9(3):4784-807. <DOI $>$.

6. Eyley $S$, Thielemans W. Surface modification of cellulose nanocrystals. Nanoscale. 2014;6(14):7764-79. <DOI $>$.

7. Habibi Y, Lucia LA, Rojas OJ. Cellulose Nanocrystals: Chemistry, Self-Assembly, and Applications. Chem Rev. 2010 Jun $9 ; 110(6): 3479-500$. $\leq$ DOI $>$.

8. George J, S N S. Cellulose nanocrystals: synthesis, functional properties, and applications. NSA. 2015 Nov;45. $\leq \mathrm{DOI}>$.

9. Anwar Z, Gulfraz M, Irshad M. Agro-industrial lignocellulosic biomass a key to unlock the future bioenergy: A brief review. Journal of Radiation Research and Applied Sciences. 2014 Apr;7(2):163-73. <DOI $>$.

10. Abitbol T, Rivkin A, Cao Y, Nevo Y, Abraham E, BenShalom T, et al. Nanocellulose, a tiny fiber with huge applications. Current Opinion in Biotechnology. 2016 Jun;39:76-88. $\leq$ DOI $>$.

11. Yang J. Manufacturing of Nanocrystalline Cellulose [Internet] [Master of Science Thesis]. [Finland]: Aalto University School of Chemical Engineering; 2017. $\leq U R L>$.

12. Faruk O, Bledzki AK, Fink H-P, Sain M. Biocomposites reinforced with natural fibers: 2000-2010. Progress in

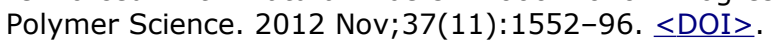

13. Ng H-M, Sin LT, Tee T-T, Bee S-T, Hui D, Low C-Y, et al. Extraction of cellulose nanocrystals from plant sources for application as reinforcing agent in polymers. Composites Part B: Engineering. 2015 Jun;75:176-200. $\leq \mathrm{DOI}>$.

14. Rosa MF, Medeiros ES, Malmonge JA, Gregorski KS, Wood DF, Mattoso LHC, et al. Cellulose nanowhiskers from coconut husk fibers: Effect of preparation conditions on their thermal and morphological behavior. Carbohydrate Polymers. 2010 May;81(1):83-92. <DOI>.

15. Manzato L, Rabelo LCA, de Souza SM, da Silva CG, Sanches EA, Rabelo $D$, et al. New approach for extraction of cellulose from tucumã's endocarp and its structural characterization. Journal of Molecular Structure. 2017 Sep;1143:229-34. <DOI $>$.

16. Gooch JW, editor. Encyclopedic dictionary of polymers. 2nd ed. New York: Springer; 2011. 1 p. ISBN: 978-14419-6246-1.

17. Rodsamran $\mathrm{P}$, Sothornvit R. Renewable cellulose source: isolation and characterisation of cellulose from rice stubble residues. Int J Food Sci Technol. 2015 Sep;50(9):1953-9. <DOI $>$.

18. Segal L, Creely JJ, Martin AE, Conrad CM. An Empirical Method for Estimating the Degree of Crystallinity of Native 
Cellulose Using the X-Ray Diffractometer. Textile Research Journal. 1959 Oct;29(10):786-94. <DOI $>$.

19. Şahin GG, Karaboyacl M. Process and machinery design for the recycling of tetra pak components. Journal of Cleaner Production. 2021 Nov;323:129186. <DOI>.

20. Lee HV, Hamid SBA, Zain SK. Conversion of Lignocellulosic Biomass to Nanocellulose: Structure and Chemical Process. The Scientific World Journal. 2014;2014:1-20. <DOI $>$.

21. Santos RM dos, Flauzino Neto WP, Silvério HA, Martins DF, Dantas NO, Pasquini D. Cellulose nanocrystals from pineapple leaf, a new approach for the reuse of this agrowaste. Industrial Crops and Products. 2013 Oct;50:70714. $\leq \mathrm{DOI}>$.

22. Fahma F, Iwamoto S, Hori N, Iwata T, Takemura A. Isolation, preparation, and characterization of nanofibers from oil palm empty-fruit-bunch (OPEFB). Cellulose. 2010 Oct;17(5):977-85. <DOI $>$.

23. Lu P, Hsieh Y-L. Preparation and characterization of cellulose nanocrystals from rice straw. Carbohydrate Polymers. 2012 Jan;87(1):564-73. <DOI.

24. Ciolacu D, Ciolacu F, Popa V. Amorphous celluloseStructure and characterization. Cellul Chem Technol. 2011;45((1-2)):13-21. <URL>.

25. Alemdar A, Sain M. Isolation and characterization of nanofibers from agricultural residues-Wheat straw and soy hulls. Bioresource Technology. 2008 Apr;99(6):1664-71. $\leq \mathrm{DOI}>$.

26. Fan M, Dai D, Huang B. Fourier Transform Infrared Spectroscopy for Natural Fibres. In: Salih Mohammed Salih, editor. Fourier Transform-Materials Analysis [Internet]. 2012 [cited 2021 Dec 18]. ISBN: 978-953-514293-5. $\leq U R L>$.

27. Chieng B, Lee S, Ibrahim N, Then Y, Loo Y. Isolation and Characterization of Cellulose Nanocrystals from Oil Palm Mesocarp Fiber. Polymers. 2017 Aug 11;9(12):355. $\leq$ DOI $>$.

28. Mazlita Y, Lee HV, Hamid SBA. Preparation of Cellulose Nanocrystals Bio-Polymer from Agro-Industrial Wastes: Separation and Characterization. Polymers and Polymer Composites. 2016 Nov;24(9):719-28. <DOI>.

29. Kumar A, Singh Negi Y, Choudhary V, Kant Bhardwaj N. Characterization of Cellulose Nanocrystals Produced by Acid-Hydrolysis from Sugarcane Bagasse as Agro-Waste. JMPC. 2020 Oct 29;2(1):1-8. <DOI 2 .

30. Feng X, Meng X, Zhao J, Miao M, Shi L, Zhang S, et al. Extraction and preparation of cellulose nanocrystals from dealginate kelp residue: structures and morphological characterization. Cellulose. 2015 Jun;22(3):1763-72. $\leq \mathrm{DOI}$.

31. Dai $H$, Ou S, Huang $Y$, Huang $H$. Utilization of pineapple peel for production of nanocellulose and film application. Cellulose. 2018 Mar;25(3):1743-56. <DOI 2.

32. Oushabi A, Sair S, Oudrhiri Hassani F, Abboud $Y$ Tanane O, El Bouari A. The effect of alkali treatment on mechanical, morphological and thermal properties of date palm fibers (DPFs): Study of the interface of DPFPolyurethane composite. South African Journal of Chemical Engineering. 2017 Jun;23:116-23. <DOI $>$.

33. Rosli NA, Ahmad I, Abdullah I. Isolation and Characterization of Cellulose Nanocrystals from Agave angustifolia Fibre. BioResources. 2013 Feb 21;8(2):1893908. $\leq$ DOI $>$.

34. Nascimento SA, Rezende CA. Combined approaches to obtain cellulose nanocrystals, nanofibrils and fermentable sugars from elephant grass. Carbohydrate Polymers. 2018 Jan;180:38-45. <DOI>.

35. Khawas $P$, Deka SC. Isolation and characterization of cellulose nanofibers from culinary banana peel using highintensity ultrasonication combined with chemical treatment. Carbohydrate Polymers. 2016 Feb;137:608-16. $\leq$ DOI $>$.

36. Lamaming J, Hashim R, Leh $\mathrm{CP}$, Sulaiman $\mathrm{O}$, Sugimoto $T$, Nasir M. Isolation and characterization of cellulose nanocrystals from parenchyma and vascular bundle of oil palm trunk (Elaeis guineensis). Carbohydrate Polymers. 2015 Dec;134:534-40. <DOI $>$.

37. Sonia A, Priya Dasan K. Chemical, morphology and thermal evaluation of cellulose microfibers obtained from Hibiscus sabdariffa. Carbohydrate Polymers. 2013 Jan;92(1):668-74. <DOI $>$.

38. Rhim J-W, Reddy JP, Luo X. Isolation of cellulose nanocrystals from onion skin and their utilization for the preparation of agar-based bio-nanocomposites films. Cellulose. 2015 Feb;22(1):407-20. <DOI $>$.

39. Mandal A, Chakrabarty D. Isolation of nanocellulose from waste sugarcane bagasse (SCB) and its characterization. Carbohydrate Polymers. 2011 Aug;86(3):1291-9. <DOI $>$.

40. Meng F, Wang G, Du X, Wang Z, Xu S, Zhang Y. Extraction and characterization of cellulose nanofibers and nanocrystals from liquefied banana pseudo-stem residue. Composites Part B: Engineering. 2019 Mar;160:341-7. $\leq \mathrm{DOI}>$.

41. Naduparambath S, T.V. J, V. S, M.P. S, Balan AK, E. P. Isolation and characterisation of cellulose nanocrystals from sago seed shells. Carbohydrate Polymers. 2018 Jan;180:13-20. <DOI >.

42. Liu D, Zhong $\mathrm{T}$, Chang PR, Li K, Wu Q. Starch composites reinforced by bamboo cellulosic crystals. Bioresource Technology. 2010 Apr;101(7):2529-36. $\leq \mathrm{DOI}>$.

43. C.S. JC, George N, Narayanankutty SK. Isolation and characterization of cellulose nanofibrils from arecanut husk fibre. Carbohydrate Polymers. 2016 May;142:158-66. $\leq$ DOI $>$.

44. Prado KS, Spinacé MAS. Isolation and characterization of cellulose nanocrystals from pineapple crown waste and their potential uses. International Journal of Biological Macromolecules. 2019 Feb;122:410-6. <DOI $>$. 
Akgün D, Ova Özcan D, Övez B. JOTCSA. 2022; 9(1): 131-148. 